\title{
Are interventions to reduce the impact of arsenic contamination of groundwater on human health in developing countries effective? A systematic review
}

Tracey Jones-Hughes ${ }^{1 *}$, Jaime Peters ${ }^{1}$, Rebecca Whear ${ }^{1}$, Chris Cooper ${ }^{1}$, Hywel Evans $^{2}$, Michael Depledge ${ }^{3}$ and Mark Pearson ${ }^{1}$

\begin{abstract}
Background: Within developing countries, groundwater provides an alternative drinking source to polluted surface water. However, the presence of arsenic in some groundwater sources has resulted in chronic worldwide poisoning. The aim of this review was to determine the effectiveness of field-based technologies for the removal of arsenic from groundwater in developing countries.

Methods: A structured search strategy was conducted in a range of databases. Titles, abstracts and full texts were screened using pre-defined inclusion criteria. Included studies were quality appraised prior to data extraction. The primary outcome was the percentage of effluent water samples meeting WHO guidelines for arsenic concentrations ( $\leq 0.01 \mathrm{mg} / \mathrm{L}$ ). Secondary outcomes included: (a) arsenic concentrations in effluent water samples meeting the national guideline limit ( $\leq 0.05 \mathrm{mg} / \mathrm{L}$ ), (b) arsenic concentrations in human tissue, and (c) knowledge and attitudes related to the interventions.

Results: Fifty-one reports, evaluating 50 different technologies, were included. Sixty-seven percent $(n=34)$ of studies were conducted in Bangladesh. Fifty of the included reports were appraised as 'weak', with one 'strong' report of a randomised-controlled trial.

In summary, the effectiveness of the oxidation and filtration interventions is poor, while the evidence for coagulation, co-precipitation and filtration, subterranean and membrane and electrolytic methods is mixed. Evidence regarding adsorption and zero valent iron interventions is more persuasive with most results suggesting good evidence of effectiveness (i.e. $\geq 95 \%$ of samples with arsenic concentrations $\leq 0.01 \mathrm{mg} / \mathrm{L}$ ). In particular, activated alumina and sono/three-kolshi/gagri/pitcher filters have $\geq 95 \%$ of samples meeting national guidelines. Disappointingly, only one study reports excellent evidence of effectiveness: BRAC (2000) for activated alumina (i.e. $\geq 95 \%$ of samples with arsenic concentrations $\leq 0.01 \mathrm{mg} / \mathrm{L}$ ).

The success of each technology was highly dependent on context, especially their acceptability to users, a sense of ownership and expectations of women's roles in society.

Conclusions: Most studies were poorly conducted and reported. Consequently, although some technologies met national guidelines, the evidence-base for decision-making regarding arsenic mitigation technologies at household- and community-level is weak. To improve this situation, primary research needs to be commissioned with adequate sample sizes, testing the impact of key contextual factors, using valid tools for analysis, and meeting standards for completeness of reporting.
\end{abstract}

Keywords: Arsenic mitigation, Arsenicosis, Drinking water, Groundwater, Developing countries, Systematic review

\footnotetext{
* Correspondence: t.jones-hughes@exeter.ac.uk

${ }^{1}$ Peninsula Technology Assessment Group, University of Exeter Medical

School, Veysey Building, Salmon Pool Lane, Exeter EX2 4SG, UK

Full list of author information is available at the end of the article
} 


\section{Background}

Arsenic is now recognised to be one of the world's greatest environmental hazards, threatening the lives of several hundred million people [1]. Whilst it has been used by humans for thousands of years in medicines and pigments, it is the naturally occurring arsenic, existing in rocks and soils, leaching into underground water which is the concern of this review. This form of arsenic, drawn from the ground by wells and used for drinking, is one of the most toxic and carcinogenic of all the natural groundwater contaminants [1].

Natural arsenic pollution occurs in diverse geological and climatic conditions. Although it occurs most commonly in sands deposited by large rivers, arsenic contaminated groundwater can be found in unconsolidated sediments and sedimentary, igneous and metamorphic rocks ranging from a few thousand to more than a billion years old [1]. As such, 21 countries are now recognised as experiencing arsenic groundwater contamination [2].

Of these 21 countries by far the worst pollution is found in Asia, along a particular band running from Pakistan to Taiwan, referred to as the South and Southeast Asian Belt [1]. The main drinking water in this region is extracted from shallow alluvial aquifers, which provide an alternative to polluted surface water and thereby reduce the incidence of water-borne diseases. However, arsenic is tasteless, odourless and colourless, therefore in areas such as Bangladesh and West Bengal in India, where the groundwater arsenic concentrations frequently exceed the WHO guidelines of $0.01 \mathrm{mg} / \mathrm{L}$ more than tenfold, these unacceptably high levels have gone undetected for a number of years [2-4].

Pollution of alluvial aquifers has also resulted in cases of arsenicosis in other countries in Southeast Asia including Vietnam, Nepal, Cambodia and China [5]. While there are few reported occurrences of arsenic contamination in Africa, it may be that the groundwater has simply not been tested.

The health consequences of long term exposure to elevated concentrations of arsenic are severe. Conditions include skin, lung, bladder and kidney cancer as well as pigmentation changes, skin thickening (hyperkeratosis), neurological and circulatory disorders, muscular weakness, loss of appetite and nausea [6]. Furthermore, because the effects of arsenic depend on cumulative exposure, the symptoms are most commonly seen in adults. As symptoms develop, a person's ability to live a normal life is reduced. Sufferers may become unable to work, severely affecting the welfare of their families. The stigma of arsenic (As) poisoning also gives rise to social impacts such as ostracism and social exclusion [1].

There are three approaches to the mitigation of arsenic groundwater contamination: (i) removing As from groundwater, (ii) developing As-free sources, and (iii) developing surface water sources. Since the intention of this review was to evaluate interventions aimed at reducing the impact of arsenic contamination of groundwater, removal was the focus.

Interventions to reduce arsenic contamination of groundwater can be broadly classified according to the primary process of arsenic removal (see Table 1).

\section{Objective of the review Primary question}

Are interventions to reduce the impact of arsenic contamination of groundwater on human health in developing countries effective?

The primary question was developed in consultation with AusAID and modified according to feedback received from the Collaboration for Environmental Evidence (CEE) and two external peer reviewers. However, it should be noted that this review is only part of the 'overall picture' of decreasing arsenic contamination of drinking water. The following factors are also likely to play an important role, but are not covered by this review:

1) Education of people who are exposed to As contaminated drinking water and subsequent behaviour change.

2) Exposure to arsenic through consumption of foodstuffs.

3) Co-ordination and monitoring of As mitigation strategies.

4) Technology choices.

5) Level of institutional support to communities and households.

\section{Secondary question}

What factors enable or constrain the effectiveness of these interventions in developing countries?

\section{Methods}

\section{Searches}

The literature search for this review was conducted in two stages:

1) A search of databases; and,

2) Citation chasing, pearl-growing and web-searching.

\section{Search terms and languages}

The search syntax was formulated to use arsenic (the term was truncated arsen* to capture arsenates or arsenates or other species of arsenic prevalent in groundwater [7] and water, or groundwater. This syntax was split into search clusters which were joined with the Boolean connector AND to give items which made reference in the title and/or abstract and/or keyword to (arsen*) AND (water or groundwater). The search was 
Table 1 Processes to remove arsenic from groundwater (adapted from Ravenscroft et al., 2009)

\begin{tabular}{|c|c|}
\hline Technology (Intervention) & Mechanism of action \\
\hline \multicolumn{2}{|l|}{ Treatment of water } \\
\hline \multirow[t]{5}{*}{ Oxidation and filtration } & $\begin{array}{l}\text { Oxidation of iron or manganese of which the oxyhydroxides adsorb arsenic prior to filtration or } \\
\text { sedimentation. }\end{array}$ \\
\hline & Or; \\
\hline & $\begin{array}{l}\text { Passive oxidation and sedimentation which requires high iron concentrations in the source water. } \\
\text { Oxygen from the air mixes with the water causing iron to precipitate and arsenic to co-precipitate. }\end{array}$ \\
\hline & Or; \\
\hline & $\begin{array}{l}\text { Slow sand filtration. Aeration causes oxidation and precipitation of iron. Arsenic may be removed by } \\
\text { direct adsorption onto iron precipitate or oxidised by bacteria growing on filter. }\end{array}$ \\
\hline Coagulation, co-precipitation and filtration & Addition of metal salts to water, producing flocs onto which arsenic is adsorbed. \\
\hline Lime softening & $\begin{array}{l}\text { Tends to be used at large treatment plants to raise } \mathrm{pH} \text {. Uses precipitating mechanism to remove } \\
\text { arsenic. }\end{array}$ \\
\hline Adsorption processes & $\begin{array}{l}\text { Relies on the adsorption of arsenic onto the surfaces of adsorbents such as activated alumina, } \\
\text { synthetic iron hydroxides, iron oxide coated sands, greensand filtration, manganese oxides, titanium } \\
\text { oxide, cerium oxide, biological adsorptive filtration and water hyacinth. }\end{array}$ \\
\hline Zero-valent iron & $\begin{array}{l}\text { Refers to the use of iron filings or nails. The process appears to work by either co-precipitation and } \\
\text { adsorption on iron oxyhydroxde, or, when used with sulphate, by forming arsenopyrite. }\end{array}$ \\
\hline lon exchange & $\begin{array}{l}\text { lon exchange resins are only effective for charged ions and so only works well for arsenic in the } \\
\text { form of arsenates }(\operatorname{As}(V)) \text {. }\end{array}$ \\
\hline Membrane technologies & $\begin{array}{l}\text { Membrane filtration relies on synthetic membranes containing billions of microscopic holes that act } \\
\text { as selective barriers to the movement of molecules under the influence of a pressure gradient, such } \\
\text { as reverse osmosis and nanofiltration. }\end{array}$ \\
\hline Electrolytic methods & $\begin{array}{l}\text { A complex form of ion exchange controlled by alternating electric currents in which ions migrate } \\
\text { from the less to the more concentrated solution. }\end{array}$ \\
\hline Phytofiltration & An emerging technology where plants are used to remove contaminants from water. \\
\hline Arsenic removal in situ & $\begin{array}{l}\text { Works by modifying the redox conditions in an aquifer, exploiting the capacity of iron } \\
\text { oxyhydroxides to adsorb arsenic. }\end{array}$ \\
\hline
\end{tabular}

conducted in the English language. Please see Additional file 1 for further details.

In resources with no controlled syntax, or where the specificity of the search was lost given the broad remit of some of the search resources (i.e. Web of Science), we used a population filter to increase the specificity of search returns to developing countries. This filter named not only countries but also populations, and included a cross-check of developing countries, or third world terminology (i.e. under-developed), to maintain sensitivity. The list of named countries was developed from the funder's list of includable countries (www.ausaid.gov.au/ ngos/Pages/devel_list.aspx) - which was, in turn, crosschecked with the International Human Development Indicators (http://hdr.undp.org/en/statistics/). The IMF list of developing countries was also consulted. This filter was extensively tested in scoping against known includable studies.

All searching was limited as follows:

\section{Date}

1980-current (the period in which arsenic contamination of groundwater became widely recognised and interventions to address the problem were introduced) (Ravenscroft et al., 2009).

\section{Language}

Searches were limited to the English language, as early scoping searches indicated that this is the language of publication for scientific studies in countries where arsenic contamination of groundwater is an issue.

A full record of the search approach and searches as run is included in Additional file 1.

\section{Databases}

The following databases were searched:

- Assia via CSA

- Aqualine via ProQuest

- Biosis via ISI (Thompson Reuters)

- CAB Abstracts via Ebsco HOST

- Compendex via Engineering Village

- The Cochrane Library via http://www. thecochranelibrary.com

- Embase via OVID

- ERIC via CSA 
- GreenFILE via EbscoHost

- HMIC via OVID

- IBSS via CSA

- Inspec via ISI (Thompson Reuters)

- Lilacs via http://regional.bvsalud.org/php/index.php? lang=en

- Medline via OVID

- Medline in Process via OVID

- NTIS via Enginering Village

- Pollution Abstracts via ProQuest

- PsycINFO via OVID

- Scopus via Scopus

- Sociological Abstracts via CSA

- Web of Science (CPCO-S/CPCO-SSH, SSCI) via ISI (Thompson Reuters)

- World Wide Political Science Abstracts (WPSA) via CSA

Searches for grey literature: contacts, internet searches, use of specific search terms or strings, filtering or limitations

The following web-resources, web-sites and organisations of note were searched, alongside conference abstracts (as above), library catalogues and Google, for grey, or difficult to locate, literature $[8,9]$.

\section{Web-resources}

- BL (British library) Direct and British Library Catalogue

- British Library for Development Studies (BDLS)

- Directory of Open Access Journals

- ELDIS

- Evidence-Based Policy in Development Network (EBPDN)

- Global Development Network (GDN)

- Google

- Index to Theses

- JOLIS

- RAPID (Research and Policy in Development)

- R4D Database

- The World Bank

- WHOLIS (World Health Organisation)

- WHO Regional Databases

\section{Organisations of note}

- African Development Bank

- African Medical and Research Foundation

- Asian Development Bank

- Australian Aid Agency

- British Geographical Survey

- Canadian International Development Agency

- Centers for Disease Control and Prevention
- Christian Aid

- Danish Development Agency

- Department for International Development

- European Commission

- Fresh Water Action Network

- GTZ (GIZ) Deutsche

- Inter-American Development Bank

- International Rescue Committee

- International Water Management Institute

- IRC (International Rescue Committee) International

- Japan Bank for International Cooperation

- Japan International Cooperation Agency

- Organisations of the United Nations (UNICEF, UNEP, UNDP, UN-HABITAT, UNRISD, FAO)

- Oxfam

- Overseas Development Agency

- Pan American Health Organisation

- Red Cross

- Swedish Development Agency

- US Agency for International Development

- Water and Sanitation Centre

- WaterAid

- World Bank (Office of Evaluation and Development)

- World Health Organisation

\section{Citation chasing}

Citation chasing was conducted on items included after full-text screening. Backwards citation chasing was conducted manually through reference scanning of bibliographies. Forwards citation chasing was conducted in Web of Knowledge (ISI Thompson Reuters).

The results from the citation chase were aggregated and de-duplicated against each other and the main review libraries (which contains the items from the main search and which have already been screened). This gave an additional 143 references to be screened. The results from the forwards citation chasing can be found in Additional file 1.

\section{Study inclusion criteria}

After the searches had been completed relevant studies were identified through two stages of screening. All titles and abstracts returned by the search strategy were screened by one of three reviewers (with a random sample of $10 \%$ being checked by a second reviewer). Where it was not clear from the title and abstract alone if the study met the inclusion criteria, the full-text of the study was retrieved to enable the second stage of screening also conducted by one of three reviewers (with a random sample of $25 \%$ being checked by a second reviewer). All disagreements about study inclusion and exclusion were resolved by discussion, and where necessary the involvement of a third reviewer. A kappa analysis was not conducted. 
In order to be included, the study had to fulfil the following criteria:

\section{Population (or 'subject')}

The outcomes of interest involve both groundwater and people, therefore the subjects are either people living in, or groundwater sources in, developing countries (as defined by AusAID; see Additional file 2).

\section{Intervention}

A study of any technology (see Table 1) designed to remove or lower arsenic concentration in water intended for human consumption and tested in the community/household (field setting). This does NOT include national or local policy or specific educational interventions.

\section{Comparators}

Studies had to include a form of comparison e.g. pre/ post comparison of filtered and unfiltered water, comparison with another technology intended to remove or lower arsenic concentration in groundwater, or comparison with no intervention.

\section{Outcomes}

All outcomes must be measured in field based studies and include either:

1) Arsenic concentration in groundwater intended for human consumption.

2) Arsenic concentration in human tissue or body fluids.

3) Observation of people's behaviour relating to technologies intended to remove or lower arsenic concentration in groundwater intended for human consumption.

4) People's knowledge or attitudes relating to technologies intended to remove or lower arsenic concentration in groundwater intended for human consumption.

Since this review was concerned with the viability of interventions during 'real-life' scenarios, a distinction was made to include only field tests which involved members of the community, as opposed to being operated solely by researchers.

\section{Study design}

Only comparative study designs were included (including, but not limited to, randomised controlled trials, before and after studies, and cross-sectional studies).

\section{Exclusion criteria}

Any studies which looked at the following topics were excluded from this review:

- Reduction of As contamination of rice by alternative methods of cooking, water management and irrigation.

- Reduction of As contamination in soil.

- Reduction of As in water by ferns grown in a hydroponic system, as opposed to field study.

- Nutritional supplements/intervention to minimise impact of As.

- Methods of As detection.

- Hydrogeological studies investigating actions which mobilise As.

Interventions such as dugwells, pond sand filters, rain water harvesting mechanisms, well-switching and GIS modelling were also excluded from the review since they do not reduce or remove arsenic from groundwater.

\section{Study quality assessment}

The studies included at full text were assessed using the McMaster University Effective Public Health Practice Project quality appraisal tool (www.ephpp.ca/tools.html; see Additional file 3). This tool is suitable for use across a wide range of quantitative study designs and has explicit criteria for rating selection bias, study design, confounders, blinding, data collection methods, withdrawal, intervention integrity and analyses as 'strong,' 'moderate', or 'weak'. Study quality appraisal was conducted by one of three reviewers, with a random sample of $25 \%$ checked by a second reviewer. Disagreements were resolved by discussion, with the involvement of a third reviewer if necessary.

\section{Data extraction strategy}

Data was extracted from included studies by one of three reviewers using a modified version of a data extraction form designed for use with complex public health studies [10]. Extracted data followed the outcomes described above and included details of the population, type of intervention, and context in which implemented - see Additional file 4. A random sample of $10 \%$ of the completed data extraction forms were checked by a second reviewer. Discrepancies were resolved by discussion, with the involvement of a third reviewer if necessary.

\section{Data synthesis and presentation}

All measures of arsenic concentration in groundwater are reported as $\mathrm{mg} / \mathrm{L}$ in this review. All measures of arsenic concentration in human tissue are reported as $\mu \mathrm{g} / \mathrm{g}$ creatinine and $\mu \mathrm{g} / \mathrm{L}$ urine. 


\section{Primary outcomes}

The primary outcome is the percentage of effluent water samples, i.e., water samples treated by the intervention, with arsenic concentrations below WHO guidelines $(\leq 0.01 \mathrm{mg} / \mathrm{L})[4]$. The WHO guidelines are based on 'safe/ acceptable' levels of exposure for humans, therefore those interventions meeting WHO guidelines are providing safe water for populations. Where data were available, exact 95\% confidence intervals (CIs) for the percentage of samples meeting WHO guidelines were calculated using the binomial distribution [11]. The $95 \%$ CIs provide a measure of the uncertainty associated with the proportion of samples meeting WHO guidelines. This reflects the number of samples measured in the individual studies.

The results are presented by intervention, with interventions categorised into groupings depending on the primary processes involved.

\section{Secondary outcomes}

There are three secondary outcomes: (a) the proportion (and 95\% CIs) of effluent water samples with arsenic concentrations below the guideline limit for the country in which the study was conducted (e.g. $<0.05 \mathrm{mg} / \mathrm{L}$ in Bangladesh), (b) arsenic concentrations measured in human tissue, and (c) aspects related to acceptance of the interventions.

The primary focus of this review was to establish the effectiveness of interventions to remove arsenic from groundwater. However, the qualitative information also identified in the articles was considered important in providing a context for the effectiveness results and was therefore compiled as a summary.

\section{Overall summary of effectiveness}

To aid summarising the effectiveness of the interventions, we define four categories based on the strength of evidence (Table 2).

Arsenic concentrations measured in human tissue are also presented, where such outcomes are measured and reported in the individual studies.

\section{Table 2 Strength of effectiveness evidence}

\begin{tabular}{ll}
\hline $\begin{array}{l}\text { Effectiveness } \\
\text { evidence }\end{array}$ & Definition \\
\hline Excellent & $\begin{array}{l}\geq 95 \% \text { of effluent water samples have arsenic } \\
\text { concentrations below WHO guidelines } \\
\text { Good }\end{array}$ \\
& $\begin{array}{l}\geq 95 \% \text { of effluent water samples have arsenic } \\
\text { concentrations below national guidelines* }\end{array}$ \\
Poor & $<95 \%$ of effluent water samples have arsenic \\
& concentrations below national guidelines* \\
Inconclusive & $\begin{array}{l}\text { Unable to comment on effectiveness evidence } \\
\text { due to poor reporting of results }\end{array}$ \\
\hline
\end{tabular}

* Note that the national guideline for As concentration in water is $0.05 \mathrm{mg} / \mathrm{L}$ for all of the countries included in this review.

\section{Variations of effectiveness}

The design and setting of the technology and the characteristics of the influent water are likely to have a significant impact on the effectiveness of arsenic reduction or removal. These characteristics include [1]:

1) Arsenic and iron concentrations in the raw groundwater.

2) Cleaning, maintenance and cost of the technology.

3) Volume of treated water required (water demand).

Thus, where reported in the individual studies, we have presented and discussed evidence on variation in arsenic removal effectiveness due to these factors. Details on maintenance and flow rate (in terms of $\mathrm{L} / \mathrm{hr}$ ), whether from manufacturer guidance or from evaluation are presented. Costs associated with the technology are reported by the currency and year of the individual study. However, to allow comparison of costs across technologies, all costs have also been converted to Aus $\$$ for the year 2011 using Shemilt (2010) [12].

\section{Synthesis}

Formal synthesis of quantitative outcomes across studies, i.e. meta-analysis, was not undertaken due to poor study quality, poor reporting quality and issues of heterogeneity between studies.

The main inhibitor of meta-analysis for this review was heterogeneity in the design and conduct of studies, such as differences in the intervention being assessed and the unit of analysis (samples from different sites, repeat samples from just one site, repeat samples from a number of sites, etc.). The poor quality of study conduct also influenced our decision, as potential biases may be masked in a meta-analysis. In terms of reporting quality, the outcome data required for synthesis could not be extracted for some studies, therefore this information would be lacking from the synthesis.

Overall, conducting a meta-analysis across these studies would have produced results which would have been difficult, if not impossible, to interpret. As many informative texts state, meta-analysis of study results, when studies are diverse or of poor quality, may be meaningless, with any real differences concealed [13-16].

\section{Results}

\section{Included studies}

The databases were searched from 1980 to August 2011 and forward citation chasing was completed by November 2011. The searches identified 11457 potentially relevant articles (after de-duplication). Screening by title and abstract revealed a large proportion of the studies were laboratory based and therefore excluded. Three hundred and twenty one papers were requested for examination of full text, of which 44 were included in the review. A 
further seven articles were identified for inclusion via web searching and forward chasing of bibliographies (Figure 1).

\section{Included study characteristics}

Additional file 5 provides a summary of each study detailing the country in which the study was conducted, the size and design of the study, the interventions and outcomes assessed, and an overview of study quality. Details on interventions such as household/community, costs and flow rates are in Tables 3, 4, 5, 6, 7 and 8. Further description of study quality is given in 'Included study characteristics' and Additional file 6. Fifty of the fifty-one included studies were appraised as 'weak' using the EPHPP quality appraisal tool, with only one study (a RCT; Milton et al. (2007)) appraised as 'strong' [17]. Whilst we recognise the difficulties for decision-makers of using a synthesis of methodologically-weaker studies, we did not exclude studies on the basis of quality as:

- The comparators in the RCT were limited to one includable technology (compared with no intervention);

- From using the EPHPP quality appraisal tool, we were aware that despite it being designed for use with public health rather than clinical studies, non-randomised studies were still likely to receive a 'weak' rating'; and

- Non-randomised study designs (such as before/after) were likely to be more appropriate for assessing the effectiveness of interventions to reduce arsenic contamination in water, as this study design: o allows the direct comparison of water samples before and after the intervention.

$\circ$ makes it less likely that confounding of the comparison by location, season and/or the characteristics of different water sources (such as the chemical composition of water samples) will occur.

A key for the 'Outcomes' and 'Quality' headings in Additional file 5 is provided below. A key for the study design elements of Additional file 5 can be found in Additional file 6, but in particular, under the 'Study design' heading in Additional file 5, a straight single line indicates that a survey of one group of participants was undertaken (i.e. as in Akman \& Higano, (2002)) [18]. Two parallel straight lines indicates that a survey of two different groups of participants was undertaken (i.e. Ahmad et al. (2005) and Ahmad et al. (2006)) [19,20]. A before/after study is indicated by the elongated S-shaped line as in Ashraf Ali et al. (2001) [21]. A randomised control trial design is denoted by a straight line that splits into two as for Milton et al. (2007) in Additional file 5 [17]. The width of the lines indicate the relative number of samples collected and analysed in each study, along with the blocks under the 'No. samples' heading.

Note that in Figure 2 (the key for Additional file 5) there is no marker for moderate overall quality, since all studies were considered to be of weak or strong quality. The validity and reliability items in Additional file 5 correspond to appraisal of data collection methods from the EPHPP quality appraisal tool (Additional file 7).

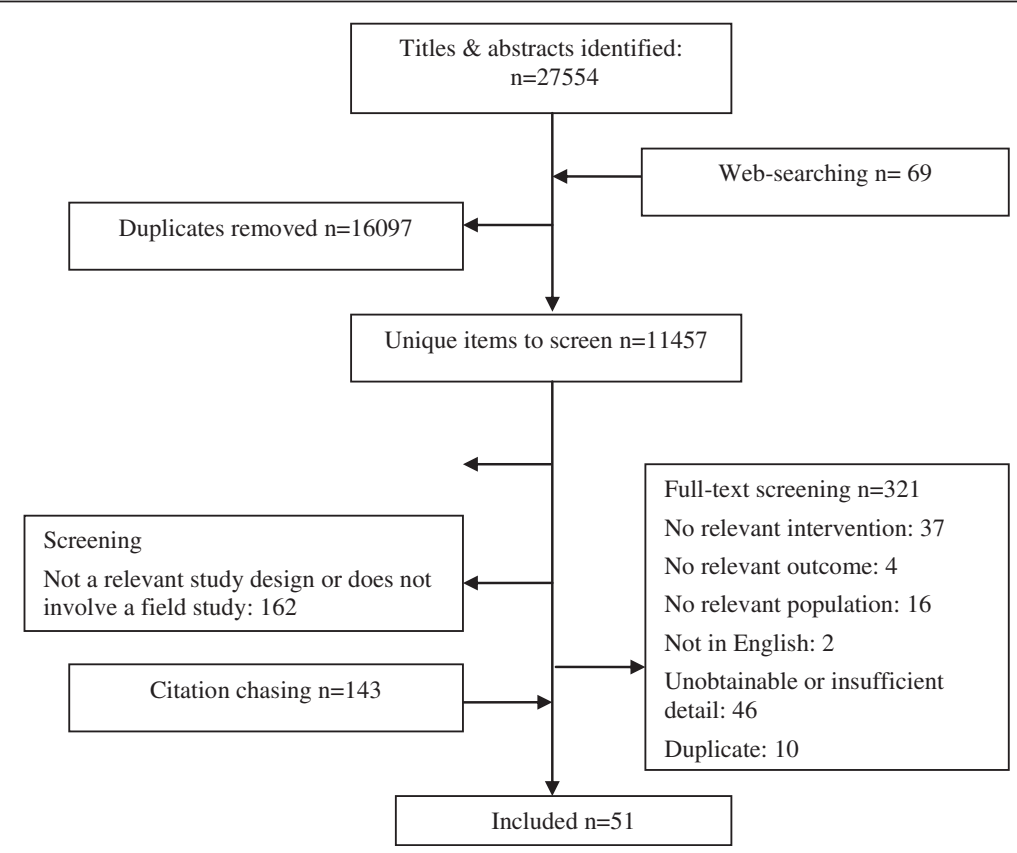

Figure 1 Summary of study selection. 
Table 3 Summary of costs and flow rates for oxidation and filtration technologies

\begin{tabular}{|c|c|c|c|c|c|}
\hline Author & Intervention & $\begin{array}{l}\text { Household or } \\
\text { community }\end{array}$ & Flow L/hr & $\begin{array}{l}\text { Capital } \\
\text { cost as Aus\$ }\end{array}$ & $\begin{array}{l}\text { Operational } \\
\text { cost as Aus\$ }\end{array}$ \\
\hline Amin (2010) & $\mathrm{MGH}$ & Household & 1.2 & $60-80$ & $0.6-0.8$ \\
\hline $\begin{array}{l}\text { Berg (2006) } \\
\text { Tobias (2011) }\end{array}$ & Sand filter & Household & $\sim 60(1 \mathrm{~L} / \mathrm{min})$ & 9.93 & Not reported \\
\hline Brennan (2011) & SPACE AIRPS & Community & 150-200 L/day & Not reported & Not reported \\
\hline Al-Muyeed (2006) & AIRPS & Community & Not reported & $200-600$ & $5-150$ \\
\hline $\begin{array}{l}\text { Sutherland (2002), } \\
\text { BAMWSP, Rahman (2005) }\end{array}$ & GARNET & Unclear & 1.2 (max $14 \mathrm{~L}$ over $12 \mathrm{hrs}$ ) & Not reported & Not reported \\
\hline BAMSWP & Ardasha filter & Unclear & 1.1 & Not reported & Not reported \\
\hline BAMSWP & Passive sedimentation & Unclear & Not reported & N/A & Not reported \\
\hline Bhattacharyya (2004) & Domestic clay candle filter & Household & Not reported & Not reported & Not reported \\
\hline Hassan (2009) & Iron oxidising bacteria & Community & 140 L/day anticipated & Not reported & Not reported \\
\hline $\begin{array}{l}\text { Sharma (2004) } \\
\text { Hassan (2008) }\end{array}$ & $\mathrm{A} / \mathrm{IRU}$ & Community & Not reported & Not reported & Not reported \\
\hline Shafiquzzaman (2011) & Iron removal ceramic filter & Household & $2.5-5.5$ & Not reported & Filter -18 \\
\hline Delowar (2006) & AANF & Household & $1.01-1.24$ & 35 & Not reported \\
\hline
\end{tabular}

- For validity: "Were data collection tools shown to be valid?"

- For reliability: "Were data collection tools shown to be reliable?"

These two items are shown in Additional file 5 as they were deemed to be important for appraising study quality in the context of interventions to remove or reduce arsenic in groundwater.

The majority of studies $(\mathrm{n}=34,67 \%)$ are based in Bangladesh, with the remaining set in India $(n=10,20 \%)$, Nepal $(\mathrm{n}=3,6 \%)$, Vietnam $(\mathrm{n}=2,4 \%)$, Cambodia $(\mathrm{n}=1$, $2 \%)$ and China $(n=1,2 \%)$. Forty-four studies (86\%) report an evaluation of the effectiveness of interventions (as

Table 4 Summary of costs and flow rates for coagulation, co-precipitation and filtration technologies

\begin{tabular}{|c|c|c|c|c|c|}
\hline Author & Intervention & $\begin{array}{l}\text { Household or } \\
\text { community }\end{array}$ & Flow L/hr & $\begin{array}{l}\text { Capital } \\
\text { cost as Aus\$ }\end{array}$ & $\begin{array}{l}\text { Operational } \\
\text { cost as Aus\$ }\end{array}$ \\
\hline $\begin{array}{l}\text { BAMWSP (2001), } \\
\text { Sutherland (2001), } \\
\text { Sutherland (2002) }\end{array}$ & $\begin{array}{l}\text { DPHE/Danida two } \\
\text { bucket system }\end{array}$ & Household & 4.3 (max 43-52 L in $12 \mathrm{hrs}$ ) & Not reported & Not reported \\
\hline Hoque (2000) & $\begin{array}{l}\text { Alum treatment of } \\
\text { contaminated water }\end{array}$ & Unclear & Not reported & Not reported & Not reported \\
\hline $\begin{array}{l}\text { BAMWSP (2001), } \\
\text { Sutherland (2001), } \\
\text { Sutherland (2002) }\end{array}$ & $\begin{array}{l}\text { Stevens Institute } \\
\text { technology }\end{array}$ & Unclear & 18 (max $211 \mathrm{~L}$ in $12 \mathrm{hrs})$ & Not reported & Not reported \\
\hline Meng (2001) & $\begin{array}{l}\text { Household co-precipitation } \\
\text { and filtration system }\end{array}$ & Household & $\begin{array}{l}90 \text { (reduced to } 24 \text { after } \\
10 \text { buckets) }(1.5 \mathrm{~L} / \mathrm{min})\end{array}$ & Not reported & 8/year/family \\
\hline Amiri (2010) & STAR & Unclear & $\begin{array}{l}16 \mathrm{~L}-\text { mixed and stand } \\
10-15 \text { min }\end{array}$ & Not reported & Not reported \\
\hline Amiri (2010) & CIWPL & Unclear & $\begin{array}{l}20 \mathrm{~L} \text { water - stirred for } \\
2 \text { mins and stand for } 1 \text { hour. }\end{array}$ & Not reported & Not reported \\
\hline Norton (2009) & $\begin{array}{l}\text { Procter \& Gamble } \\
\text { flocculant-disinfectant } \\
\text { powder }\end{array}$ & Household & $\begin{array}{l}10 \mathrm{~L} / \text { sachet. Stir } 5 \mathrm{~min} \\
\text { and settle } 5 \mathrm{~min}\end{array}$ & Not reported & Not reported \\
\hline Cheng (2004) & $\begin{array}{l}\text { Household arsenic } \\
\text { removal system }\end{array}$ & Household & $30-120(0.5-2.0 \mathrm{~L} / \mathrm{min})$ & Not reported & Not reported \\
\hline Ali (2001) & Ferric chloride coagulation & Household & $60-120(1-2 \mathrm{~L} / \mathrm{min})$ & 80 & Chemicals -0.20 \\
\hline Hossain (2005) & $\begin{array}{l}\text { Chlorinating agent } \\
(\mathrm{BP})+\text { ferric alum }\end{array}$ & Community & 1000 & $\begin{array}{l}1512 \text { periodic chemical } \\
\text { charges (assume } 2002- \\
\text { study 2001-2003) }\end{array}$ & Not reported \\
\hline
\end{tabular}


Table $\mathbf{5}$ Summary of costs and flow rates for adsorption processes

\begin{tabular}{|c|c|c|c|c|c|}
\hline Author & Intervention & $\begin{array}{l}\text { Household or } \\
\text { community }\end{array}$ & Flow L/hr & Capital cost as Aus\$ & $\begin{array}{l}\text { Operational } \\
\text { cost as Aus\$ }\end{array}$ \\
\hline Hossain (2005) & Activated alumina As-37 & Community & 600 & $\begin{array}{l}2042+622 \text { per } \\
\text { charge }+4 \% \text { sales tax }\end{array}$ & Not reported \\
\hline Hossain (2005) & $\begin{array}{l}\text { Aquabind - activated } \\
\text { alumina with metal oxide }\end{array}$ & Community & 42 (1000 L/day) & $3456+649$ per charge & Not reported \\
\hline Hossain (2005) & $\begin{array}{l}\text { Red haematite lumps + } \\
\text { quartz + sand + activated } \\
\text { alumina }\end{array}$ & Community & $600-1000$ & 1271 as per 1997 estimate & Not reported \\
\hline Hossain (2005) & $\begin{array}{l}\text { Activated alumina }+ \\
\text { AAFS-50, patented aluminium } \\
\text { silicate }+ \text { ferric hydroxide }\end{array}$ & Community & 22 (200000 L/year) & $\begin{array}{l}2080+942 \text { per media } \\
\text { charge }\end{array}$ & Not reported \\
\hline Hossain (2005) & $\begin{array}{l}\text { Aluminium silicate + ferric } \\
\text { hydroxide }\end{array}$ & Community & 83 (2000 L/day) & $376+56$ per recharge & Not reported \\
\hline Hossain (2005) & Adsorp-As (patented) & Community & 102 (900000L/year) & $3484+1177$ per charge & Not reported \\
\hline Hossain (2005) & $\begin{array}{l}\text { Slurry/granular ferric } \\
\text { hydroxide }\end{array}$ & Community & $600-900$ & $\begin{array}{l}1695+399 \text { per recharge } \\
\text { maintenance of } 56 \text { per } \\
\text { year }\end{array}$ & Not reported \\
\hline Hossain (2006) & $\begin{array}{l}\text { Samples } 305 \text { ARPs - } \\
\text { based on typical ARP } \\
\text { with granular ferric oxide }\end{array}$ & Community & Not reported & Not reported & Not reported \\
\hline $\begin{array}{l}\text { BAMWSP (2001), } \\
\text { Sutherland (2001), } \\
\text { Sutherland (2002) }\end{array}$ & $\begin{array}{l}\text { BUET activated alumina } \\
\text { filter }\end{array}$ & Household & Not reported & 1400 & 1000 \\
\hline $\begin{array}{l}\text { Amiri (2010), } \\
\text { Sutherland (2002), } \\
\text { BCSIR (2003) }\end{array}$ & ALCAN & Community & $\begin{array}{l}244->300(\max 2928 \mathrm{~L} \\
\text { over } 12 \mathrm{hrs})(5 \mathrm{~L} / \mathrm{min})\end{array}$ & 167 & Not reported \\
\hline Amiri (2010) & Apyron & Unclear & 600 (<10 L/min) & Not reported & Not reported \\
\hline Amiri (2010) & Wholly Water. & Unclear & $240(\leq 4 \mathrm{~L} / \mathrm{min})$ & Not reported & Not reported \\
\hline Amiri (2010) & Nelima & Unclear & $\begin{array}{l}20 \mathrm{~L}-\text { stir } 3 \text { or } 4 \text { times } \\
\text { (may need } 1.5-2 \text { hours if } \\
\text { over } 3 \mathrm{mg} / \mathrm{L} \text { iron }\end{array}$ & Not reported & Not reported \\
\hline Amiri (2010) & Shapla & Unclear & 5.5 & Not reported & Not reported \\
\hline Anstiss (2001) & $\begin{array}{l}\text { Tank system with ferric } \\
\text { oxide }\end{array}$ & Household & $\begin{array}{l}2.5 \text { ( } 60 \mathrm{~L} / \text { day }) \text { - flexible } \\
\text { regarding water volumes } \\
\text { and cycle length }\end{array}$ & Not reported & Not reported \\
\hline $\begin{array}{l}\text { Jakariya (2005), } \\
\text { Rahman (2005), } \\
\text { BRAC (2000) }\end{array}$ & Safi filter & Household & 40 L/day 1.7 & Not reported & $\begin{array}{l}\text { Family filter }-70 \\
\text { New candle }-\$ 20\end{array}$ \\
\hline Misra (2005) & As removal filter & Household & 15 & Not reported & Not reported \\
\hline Sarkar (2005) & $\begin{array}{l}\text { Well head treatment unit } \\
\text { using activated alumina } \\
\text { adsorption column }\end{array}$ & Community & $480-600$ & Not reported & Not reported \\
\hline $\begin{array}{l}\text { Sarkar (2008), BRAC } \\
(2000)\end{array}$ & Activated alumina & Community & 720-900 (12-15 L/min) & Not reported & Not reported \\
\hline Ali (2001) & Iron oxide coated sand & Household & $60-120$ & Not reported & Not reported \\
\hline Yuan (2002) & Iron oxide coated sand & Household & Estimate of $15 \mathrm{~L} /$ day & 52 & Not reported \\
\hline Petrusevski (2008) & UNESCO-IHE family filter & Household & $0.15-0.77$ & Not reported & Not reported \\
\hline BRAC BCSIR & SIDKO & Community & $60^{*}(11 / \mathrm{min})$ & 7200 & Media -290 \\
\hline Ashraf (2001) & Gravel bed with iron sludge & Unclear & Not reported & Not reported & Not reported \\
\hline BCSIR & READ-F & Household & $31-60$ & 256 & Not reported \\
\hline
\end{tabular}


Table 6 Summary of costs and flow rates for zero valent iron technologies

\begin{tabular}{|c|c|c|c|c|c|}
\hline Author & Intervention & $\begin{array}{l}\text { Household or } \\
\text { community }\end{array}$ & Flow L/hr & $\begin{array}{l}\text { Capital } \\
\text { cost as Aus\$ }\end{array}$ & $\begin{array}{l}\text { Operational } \\
\text { cost as Aus\$ }\end{array}$ \\
\hline $\begin{array}{l}\text { BAMWSP (2001), Sutherland (2001), } \\
\text { Hussam (2007), Jakariya (2005), } \\
\text { Neku (2003), Shafiquzzaman (2009), } \\
\text { Sutherland (2002), Milton (2007), } \\
\text { BRAC (2000), BCSIR (2003), } \\
\text { Delowar (2006) }\end{array}$ & $\begin{array}{l}\text { SONO - } 3 \text { kolshi arsenic } \\
\text { filter-three gagri-three pitcher }\end{array}$ & Household & $2.1-20$ & 9.7 & $16 / 5$ years \\
\hline Ngai (2007), Ngai (2006), Uy (2009) & Kanchan filter & Household & $\begin{array}{l}30-42 \text { Initially max of } \\
0.7 \mathrm{~L} / \mathrm{min} \text { dropping to } \\
\sim 0.2 \mathrm{~L} / \mathrm{min} \text { before cleaning }\end{array}$ & 36 & 4-9/year \\
\hline BRAC (2000) & Tubewell Sand Filter & Community & Not reported & Not reported & Not reported \\
\hline
\end{tabular}

indicated in column 3 of Additional file 5, under the "Outcome/Effectiveness" heading). Across these effectiveness studies there is great variation in the number of water samples measured, ranging from two samples reported in Oh et al. (2000) to 1074 samples reported in Ngai et al. (2006) [22,23]. In addition, there are differences in the sample units across studies. For example, some studies report repeated samples over a period of days at one site [24], while other studies report on repeated samples at a number of wells at a number of sites [25]. For eight studies it is unclear whether a reported value is a single measurement or an average of an unknown number of measurements.

Six studies (12\%) report on the effectiveness of interventions and provide detail on behavioural aspects related to the use of these interventions. A further seven studies (14\%) provide evidence on behavioural aspects only. Studies assessing behavioural aspects generally have a large number of participants, e.g. Ahmad et al. (2006) reports on a study of 2700 households and Jakariya et al. (2007) who surveyed 2600 families [20,26].

Of the 44 studies reporting on the effectiveness of interventions, all but one of these are before and after studies where influent and effluent water samples are analysed and compared for their arsenic content. The remaining study is a randomised control trial, where households are randomised to receive the intervention or to receive no intervention.
The most common design for the studies reporting on behavioural aspects of arsenic removal/reduction interventions is that of a survey where users of different interventions are surveyed at a particular time-point.

Across the 51 included studies, 50 different interventions are described. The wide range of technologies appears to be due to attempts to meet the varying needs of villagers in terms of availability of resources, cost, maintenance, and ease of use. In order to appraise the effectiveness of the interventions, they were classified into eight groups based on the primary process involved in the intervention as described by Ravenscroft et al. (2009) [1]:

- Oxidation and filtration

- Coagulation, co-precipitation and filtration

- Adsorption

- Ion exchange

- Zero valent iron

- Arsenic removal in situ

- Membrane

- Electrolytic

For example, the 3-kolshi filter, as evaluated in BRAC (2000), is defined as a zero valent iron intervention since this employs the solid elemental form of iron as filings or nails [27]. Details of the groups, the specific interventions and the primary processes involved are given in Table 9.

Table 7 Summary of costs and flow rates for ion exchange technologies

\begin{tabular}{|c|c|c|c|c|c|}
\hline Author & Intervention & $\begin{array}{l}\text { Household or } \\
\text { community }\end{array}$ & Flow L/hr & Capital cost as Aus\$ & $\begin{array}{l}\text { Operational } \\
\text { cost as Aus\$ }\end{array}$ \\
\hline Hossain (2005) & AFDWS-2000 (patent pending) & Community & Up to $10000 \mathrm{~L}$ & 3242 & Not reported \\
\hline Hossain (2005) & Ferric hydroxide & Community & 600 & 1686 & Not reported \\
\hline Hossain (2005) & Bucket of resins (patented) & Community & $300000 L$ & $\begin{array}{l}3986+1686 \text { per } \\
\text { recharge }+4 \% \text { sales tax }\end{array}$ & Not reported \\
\hline $\begin{array}{l}\text { BAMWSP (2001), } \\
\text { Sutherland (2001), } \\
\text { Sutherland (2002), } \\
\text { BCSIR (2003) }\end{array}$ & Tetrahedron/Tetratreat & Unclear & $\begin{array}{l}60-120 \text { (720 over } \\
12 \text { hours) }\end{array}$ & 1300 & Not reported \\
\hline Sarkar (2007) & ArsenX & Community & $480-600$ & Not reported & Not reported \\
\hline
\end{tabular}


Table 8 Summary of costs and flow rates for in situ arsenic removal, nanofiltration and electrocoagulation

\begin{tabular}{|c|c|c|c|c|c|}
\hline Author & Intervention & $\begin{array}{l}\text { Household or } \\
\text { community }\end{array}$ & Flow L/hr & $\begin{array}{l}\text { Capital cost as } \\
\text { Aus } \$\end{array}$ & $\begin{array}{l}\text { Operational cost as } \\
\text { Aus } \$\end{array}$ \\
\hline Oh (2000) & $\begin{array}{l}\text { Low pressure nanofiltration - } \\
\text { membrane filtration }\end{array}$ & Unclear & $\begin{array}{l}17-29(290-490 \mathrm{~mL} / \mathrm{min} \\
\text { at } 4 \mathrm{MPa})\end{array}$ & Not reported & Not reported \\
\hline Gupta (2010) & Subterranean arsenic removal & Community & 250 (6000 L/day) & Not reported & $1.6 / 10 \mathrm{~m}^{3}$ \\
\hline $\begin{array}{l}\text { Van Halem } \\
\text { (2010) }\end{array}$ & Subterranean arsenic removal & Community & $1200\left(1.2 \mathrm{~m}^{3} / \mathrm{hr}\right)$ & Not reported & Not reported \\
\hline Wan (2011) & Electrocoagulation & Household & Treatment as $50 \mathrm{~L} / 3 \mathrm{hrs}$ & Not reported & $0.21 / \mathrm{m}^{3}$ \\
\hline Rott (2008) & Subterranean arsenic removal & Community & $\begin{array}{l}167 \text { - } 250(4000-6000 \text { L/ } \\
\text { day) }\end{array}$ & Not reported & Not reported \\
\hline
\end{tabular}

A summary of all interventions evaluated by each study can be found in Additional file 5 under the 'Technologies' heading. A breakdown of the number of studies and interventions included in the review is given in Figure 3, with interventions classified into the eight groupings. There are more interventions in the adsorption grouping because a number of studies have assessed a greater number of adsorption interventions than other types, in particular Amiri et al. (2010), BCSIR (2003) and BRAC (2000) (see Additional file 5) [27-29]. On the other hand, for zero valent iron technologies many studies have assessed the same type of intervention: the sono, three-pitcher/kolshi/gagri filter.

The final column of Additional file 5 details the funding source for each study. For 36 of the studies (71\%), the funding source could not be determined from the article and a further study reported no funding for their research.

\section{Study quality assessment}

The overall quality of the studies was poor, with all but one ranked as weak (Additional file 5). The one RCT was appraised as strong [17]. Fifteen studies were at least

\section{Key \\ Outcome: $\bigcirc$ Not reported Reported \\ Quality: $\bigcirc$ Not valid/reliable - Valid/reliable ¿ Unclear \\ Overall: $\boldsymbol{\square}$ Weak Strong \\ Figure 2 Key to the outcome and quality headings in Additional file 5.}

somewhat likely to have a representative population but in almost as many studies it was not possible to tell from the information available. Eighteen out of 23 relevant studies did not have enough information to be able to say what percentage of the sample population agreed to participate and most studies did not detail how the sample size was determined. Of the four that did, they were convenience samples.

- Eleven studies reported that the outcome assessor was blinded to the status of the water samples. Sixteen studies used valid measures (though not all were considered reliable), four studies reported using invalid and unreliable measures and the remaining 19 studies did not report this information about the measures that were used. Only four studies reported a drop out rate. For the remaining studies, this information was not described or was not applicable. Twelve studies do report the percentage of participants completing the study with nine studies reporting more than $80 \%$ of participants completing, however, in 11 studies this information could not be ascertained.

- Fifteen studies report over $80 \%$ of participants received the intervention allocation of interest but in the remaining appropriate studies this information was not present.

- Sixteen studies reported some information about the consistency with which the intervention was delivered/used but in ten studies this was not reported and in a further nine studies is was not possible to tell.

- In eight studies it was believed that the participants were likely to have received another unintended intervention and in 14 studies the likelihood was unclear.

- At least 18 studies reported the unit of analyses to match the unit of allocation within the study.

- In only two studies were the statistical analyses believed to be inappropriate for the results of the study [30,31]. 
Table 9 Summary of interventions with details on mechanisms, where available

\begin{tabular}{|c|c|c|}
\hline \multirow[t]{2}{*}{ Oxidation and filtration } & \multicolumn{2}{|c|}{ Passive oxidation and sedimentation } \\
\hline & Slow sand filtration & \\
\hline Amin (2010) & MGH filter & $\begin{array}{l}\text { Two bucket filter - the iron content Fe(II) of the source water is } \\
\text { converted to a hydrous ferric oxide from (Fe(III) as } \mathrm{HFeO} \text { or FeOH) } \\
\text { by aeration, which reacts with the } \mathrm{As}(\mathrm{V}) \text { species. As }(\mathrm{V}) \text { is removed } \\
\text { by adsorption, co-precipitation and sand filtration. }\end{array}$ \\
\hline Berg (2006), Tobias (2011) & Sand filter & $\begin{array}{l}\text { Pumped water trickles through the sand filter - oxic conditions, } \\
\text { assume co-ppt with co-existing Fe-OH. }\end{array}$ \\
\hline $\begin{array}{l}\text { Al-Muyeed (2006), Hoque (2000), } \\
\text { Brennan (2011a) and (2011b) }\end{array}$ & $\mathrm{A} / \mathrm{IRP}$ & Aeration/sedimentation chamber followed by filtration. \\
\hline $\begin{array}{l}\text { BAMWSP (2001), Sutherland (2001), } \\
\text { Hoque (2000), Sutherland (2002), } \\
\text { Rahman (2005), Hoque (2004) }\end{array}$ & GARNET & $\begin{array}{l}\text { Passive coagulation with iron (from alkaline brick chips) and } \\
\text { adsorption to sand. }\end{array}$ \\
\hline
\end{tabular}

\begin{tabular}{|c|c|}
\hline BAMWSP (2001), Sutherland (2001) & Ardasha filter \\
\hline $\begin{array}{l}\text { BAMWSP (2001), Sutherland (2001), } \\
\text { Hoque (2000) }\end{array}$ & Passive sedimentation \\
\hline Bhattacharyya (2004) & Domestic clay candle filter \\
\hline Hassan (2009) & Iron oxidising bacteria \\
\hline
\end{tabular}

Sharma (2005), Hassan (2008)

Shafiquzzaman (2011)

Delowar (2006)

Delowar (2006)

\section{Coagulation, co-precipitation and filtration}

BAMWSP (2001), Sutherland (2001), Sutherland (2002)

Hoque (2000)

BAMWSP (2001), Sutherland (2001), Sutherland (2002), Cheng (2004), Meng (2001)

Amiri (2010), BCSIR (2008)

Norton (2009)

Ali (2001)

Hossain (2005)

\section{Adsorption processes}

Hossain (2005)

Hossain (2006)

Amiri (2010), BCSIR (2008)

Amiri (2010), BCSIR (2008)

Amiri (2010), BCSIR (2008)

$\mathrm{A} / \mathrm{IRU}$

Iron removal ceramic filter

NIFSF adsorbed. water

CIWPL, STAR

Procter \& Gamble powder ferric hydroxide $(x 7)$ granular ferric oxide
Asian Arsenic Network (AAN) Filter

Extends the processes operating at Fe-MN removal plants by adding metal salts onto which As is

Tend to be complex, comprising a chemical feed system, mixing equipment, basins for mixing, flocculation and settlement, a filter medium and filter medium.

DPHE/Danida two bucket system Based on the addition of aluminium sulphate and permanganate.

Alum treatment of contaminated

Stevens Institute technology

Based on the addition of iron sulphate (coagulant) and hypochlorite (oxidant). Ferric sulphate - coagulation, then filter to remove flocs.

Flocculant-disinfectant.

Alum and iron coagulation

Chlorinating agent (BP) + ferric alum

Activated alumina, synthetic iron oxyhydroxide adsorbents, granular ferric hydroxide and granular ferric oxide, iron oxide coated sands

Variations on activated alumina and

Samples 305 arsenic removal plants (ARPs) - based on typical ARP with

$\begin{array}{ll}\text { Apyron } & \text { Alumina and modified alumina. } \\ \text { Nelima } & \text { Granular ferric oxide. } \\ \text { Shapla } & \mathrm{Fe}_{2} \mathrm{O}_{3} \text { impregnated brick chip. }\end{array}$




\section{Table 9 Summary of interventions with details on mechanisms, where available (Continued)}

\begin{tabular}{|c|c|c|}
\hline Amiri (2010), BCSIR (2008) & Wholly water & $\begin{array}{l}\text { Arsenic removal filter filled with } \mathrm{MnO}_{2} \text {, brass powder, ferric } \\
\text { sulphate modified alumina and granular activated carbon. Second } \\
\text { filter of activated alumina. }\end{array}$ \\
\hline Anstiss (2001) & Tank system with ferric oxide & $\begin{array}{l}\text { Synthetic ferric oxyhydroxide (suspension) - adsorbs and settles - } \\
\text { sand/gravel filter. }\end{array}$ \\
\hline $\begin{array}{l}\text { Jakariya (2003, 2005, 2007), } \\
\text { Rahman (2005), BRAC (2000) }\end{array}$ & Safi filter & $\begin{array}{l}\text { The Safi candle is prepared from laterite soil, ferric oxide, } \\
\text { manganese dioxide, aluminium hydroxide and meso-porous silica. }\end{array}$ \\
\hline Misra (2005) & As removal filter & $\begin{array}{l}\text { Reactant material is a processed waste from the steel industry, } \\
\text { followed by fine cloth filter, sand and another fine cloth filter. }\end{array}$ \\
\hline $\begin{array}{l}\text { Sarkar (2008), BRAC (2000), } \\
\text { Sarkar (2005), Amiri (2010), } \\
\text { Sutherland (2002), BCSIR (2003, 2008), } \\
\text { BAMWSP (2001), Sutherland (2001), } \\
\text { Sutherland (2002), Jakariya (2003, } \\
\text { 2007), Ahmad (2005) }\end{array}$ & \multicolumn{2}{|l|}{ Activated alumina filter } \\
\hline $\begin{array}{l}\text { Yuan (2002), Ali (2001), } \\
\text { Petrusevski (2008) }\end{array}$ & Iron oxide coated sand (IOCS) & IOCS \\
\hline $\begin{array}{l}\text { BRAC (2000), BCSIR (2003), } \\
\text { Jakariya (2003) }\end{array}$ & SIDKO & Granular iron hydroxide \\
\hline Ali (2001) & \multicolumn{2}{|l|}{ Gravel bed with iron sludge } \\
\hline BCSIR (2003) & READ-F & A proprietary filter media. Arsenic is adsorbed on the media. \\
\hline Zero-valent iron & \multicolumn{2}{|c|}{ Use of low cost iron filings/nails - process appears to work by co-precipitation and adsorption } \\
\hline $\begin{array}{l}\text { BAMWSP (2001), Sutherland (2001), } \\
\text { Hussam (2007), Jakariya (2003, 2005, } \\
\text { 2007), Neku (2003), Shafiquzzaman } \\
\text { (2009), Sutherland (2002), Milton }\end{array}$ & $\begin{array}{l}\text { SONO - } 3 \text { kolshi arsenic filter-three } \\
\text { gagri-three pitcher }\end{array}$ & $\begin{array}{l}\text { Passive coagulation with Fe and/or adsorption to sand matrix. } \\
\text { Iron filings or CIM matrix which is a mixture of metal iron and iron } \\
\text { hydroxides. }\end{array}$ \\
\hline
\end{tabular}

(2007), BRAC (2000), BCSIR (2003),

Delowar (2006), Ngai (2007), Ngai

(2006), Uy (2009), Hoque (2004),

Ahmad (2006)

\section{lon exchange}

Hossain (2005)

Hossain (2005)

Hossain (2005)

BAMWSP (2001), Sutherland (2001),

Sutherland (2002), BCSIR (2003)

Sarkar (2007)

Ferric hydroxide

Bucket of resins

Catalytic precipitation/electron exchange

Tetrahedron/Tetratreat

Ion exchange resin filter with a gentle oxidative hypochlorite pre-wash.

Arsen $X$

Anion exchange resin beads containing dispersed nanoparticles of hydrated ferric oxide.

Membrane technology

Reverse osmosis, nanofiltration, microfiltration and ultrafiltration

Oh (2000)

\section{Arsenic removal in situ}

Van Halem (2010), Gupta (2010), Rott (2008)

\section{Electrolytic methods}

Wan (2011)
Low pressure nanofiltration

\section{Via oxygenation}

Subterranean arsenic removal
Feed water pre-filtrated by microfiltration or directly applied to NF membrane (tight RO membrane).

Aerated water injected into tubewell to create oxidation zone.
Overall, the general issues with quality included:

- Small or vague sample sizes,

- No information on withdrawal,
- No information given on samples taken for analysis, e.g. filtering, blanks, blinding, number of replicates taken at one point in time or over a period of time, 


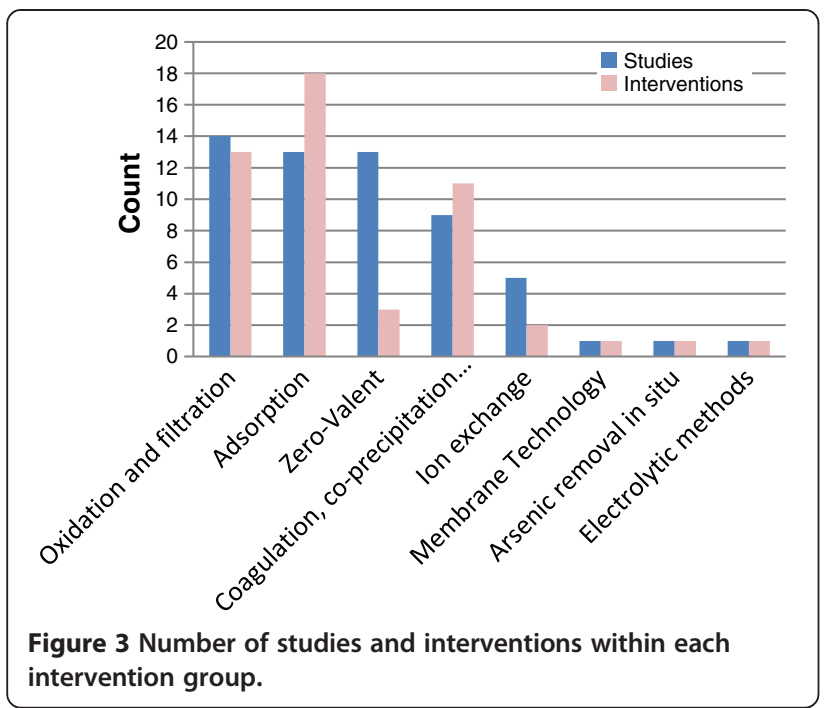

- No agreement or comparison between laboratory and field measurements,

- No details on lab accreditation,

- No participant characteristics,

- No randomisation,

- No details on intervention characteristics, e.g. household/community, costs, flow rate and maintenance requirements.

- At least four studies report that there were differences between the outcomes presented in the methods and those reported in the results $[27,28,32,33]$.

\section{Synthesis of evidence}

The effectiveness evidence for each of the intervention groupings is presented in this section. The primary outcome is the percentage of effluent water samples with arsenic concentrations below WHO guidelines $(\leq 0.01 \mathrm{mg} / \mathrm{L})$, based on 'safe/acceptable' levels of exposure for humans. There are three secondary outcomes: (a) the proportion of effluent water samples with arsenic concentrations below the guideline limit for the country in which the study was conducted (e.g. < $0.05 \mathrm{mg} / \mathrm{L}$ in Bangladesh), (b) arsenic concentrations measured in human tissue, and (c) behavioural aspects related to the use and acceptance of the interventions.

Figure 4 shows the number of studies reporting for which a quantitative effectiveness outcome is available within each intervention group. This figure also shows the number of unique interventions from these studies where effectiveness evidence is available. For instance, within the 'oxidation and filtration' group 16 studies provide effectiveness evidence for 12 different interventions, while for the 'zero valent iron' group, 13 studies provide effectiveness data for just two interventions.

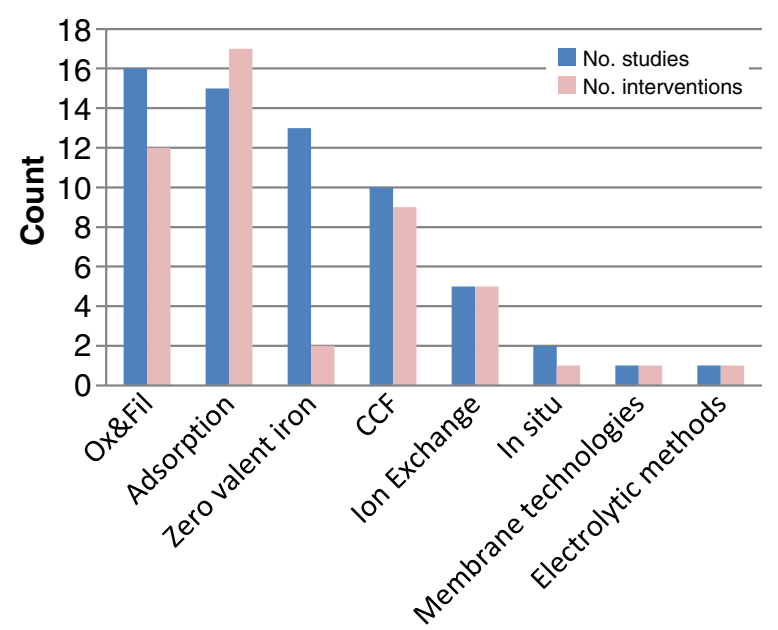

Figure 4 The number of studies and interventions for each grouping where quantitative effectiveness evidence are available.

Given that some studies evaluate a number of interventions and some interventions are evaluated across a number of studies, there are 90 potential study-by-intervention outcomes available to inform the effectiveness of arsenic removal technologies for groundwater. For 77 of these outcomes, data on the percentage of samples meeting WHO and/or national arsenic guidelines could be extracted from the study articles. For 42 of these study-by-intervention outcomes, data on the percentage of samples meeting both WHO and national guidelines for arsenic concentrations are available, while for nine and 26 of the study-by-intervention outcomes data are only available to inform the percentage of samples meeting WHO guidelines or national guidelines, respectively. These numbers are broken down by the intervention groupings in Figure 5.

For 13 study-by-intervention outcomes $(=90-77)$, data on the percentage of samples meeting WHO or national arsenic guidelines could not be extracted. This was mainly due to a lack of detail reported in the results section of the article. A list of the reasons why these data are not available for these 13 study-by-intervention outcomes is given in Additional file 8.

The available effectiveness data are presented in the following sections, by intervention grouping, for the primary outcome: the percentage of samples meeting WHO guidelines for As concentrations. First we provide detail on the interpretation of the figures in the following section.

\section{Interpretation of figures}

The solid dots in Figure 6 represent the percentage of samples meeting WHO guidelines for As concentrations for each intervention evaluated. The vertical lines above and below the solid dots represent the $95 \% \mathrm{CI}$ for the percentage of samples meeting WHO guidelines, as defined 


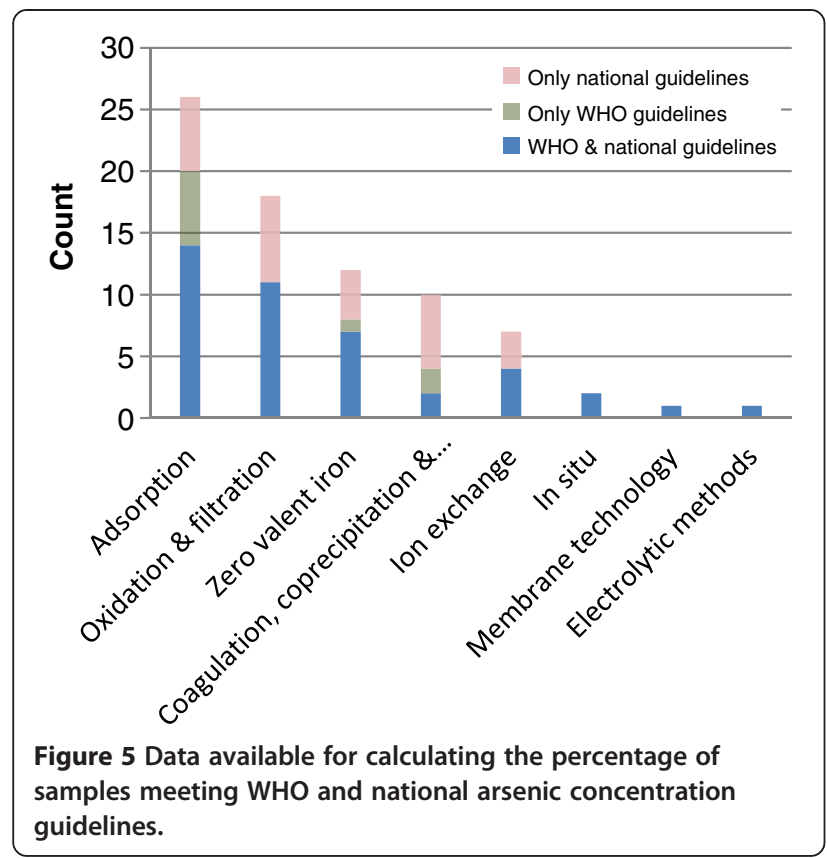

to be excellent evidence of effectiveness (see Table 2). The solid horizontal line represents the cut-off where $95 \%$ of samples meet WHO guidelines. Thus, for the sand filter, $40 \%$ of samples meet the WHO guideline (solid dot), with a $95 \%$ CI ranging from $25 \%$ to $56 \%$. The diamonds represent the approximate arsenic concentration in the influent water samples for each intervention (see right-hand-side $y$-axis of Figure 6). The dashed horizontal line represents the WHO guideline As concentration of $0.01 \mathrm{mg} / \mathrm{L}$. The approximate influent As concentration for the sand filter is $0.2 \mathrm{mg} / \mathrm{L}$. Note that where data are available, arsenic concentrations in influent water samples, except those for iron removal ceramic filters 1 and 2 (IRCF1 and IRCF2), are all well above the WHO guideline level (i.e. the dashed horizontal line). The arsenic concentrations in the influent water samples presented in Figures 6, 7, 8, 9, 10, 11 and 12 should be considered approximate as the reporting of this information is not consistent across, or even within, studies. For example, the approximate influent As concentration may reflect the median, mean or mid-point from a range of As concentrations reported in a study. For clarity, where more than one author has investigated the same technology, the abbreviation is suffixed with the author's initials. The aim is to present the reader with an understanding of the magnitude of the influent As concentration, rather than report the exact As concentration. The interpretation of Figure 6, applies equally to Figures 7, 8, 9, 10, 11 and 12.

\section{Primary outcome: Samples meeting WHO guidelines for As concentrations Oxidation and filtration technologies}

Although outcome data on 14 oxidation and filtration studies is potentially available to inform these analyses, only 11 studies provide effectiveness evidence for the proportion of samples meeting WHO guidelines (As concentration $\leq 0.01 \mathrm{mg} / \mathrm{L}$ ). These 11 studies provide data on 11 unique interventions, however the effectiveness of the iron oxidising bacteria (IOB) technology was assessed at three locations each having different influent arsenic and iron

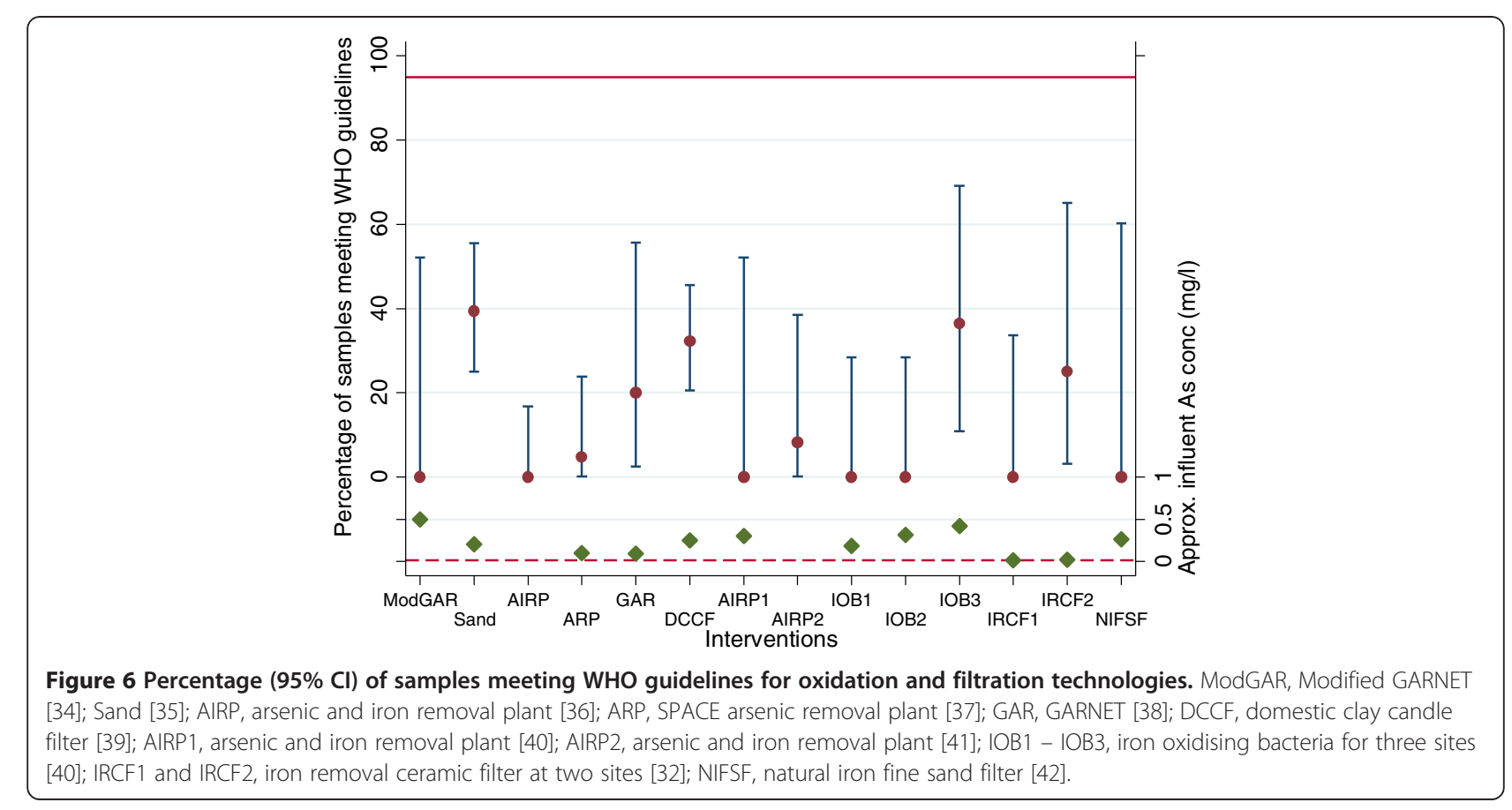




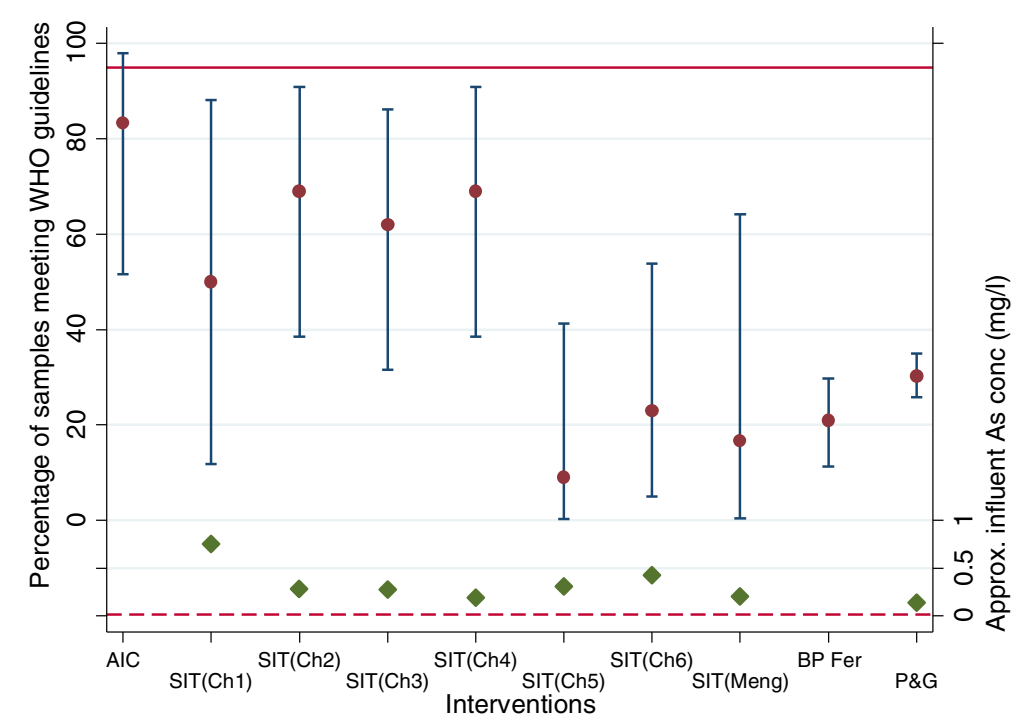

Figure 7 Percentage $(95 \% \mathrm{Cl})$ of samples meeting WHO guidelines for Coagulation, co-precipitation and filtration technologies. AlC, alum iron coagulation [21]; SIT(Ch1) - SIT(Ch6), Stevens Institute technology at six sites [43]; SIT [44], Stevens Institute technology [44]; BP Fer, BP \& ferric alum [45]; P\&G, Proctor and Gamble powder [33].

concentrations (leading to IOB1, IOB2 and IOB3) and the IRCF are reported for two different time-points (IRCF1 in April 2007 and IRCF2 in August 2007, based on dry and wet seasons). Thus, results for a total of 14 technologies are described below.

The oxidation and filtration technologies appear to perform poorly with the best performing technology, the sand filter evaluated by Berg et al. (2006), having only $40 \%$ of effluent water samples with As concentrations below the WHO guideline [35]. In fact, for half of the technologies presented in Figure 6, 0\% of samples meet the WHO guidelines (modified garnet (ModGAR), arsenic and iron removal plant (AIRP), AIRP1, IOB1, IOB2, IRCF1 and natural iron fine sand filter (NIFSF)).

There are variations in the width of the $95 \%$ CIs, with many studies having very wide $95 \%$ CIs due to the small number of samples reported; for example, the NIFSF technology reports only four samples (one sample per month for four months).

\section{Coagulation, co-precipitation and filtration technologies}

Data on the percentage of samples meeting WHO guidelines could only be determined for five of nine studies evaluating the effectiveness of coagulation, co-

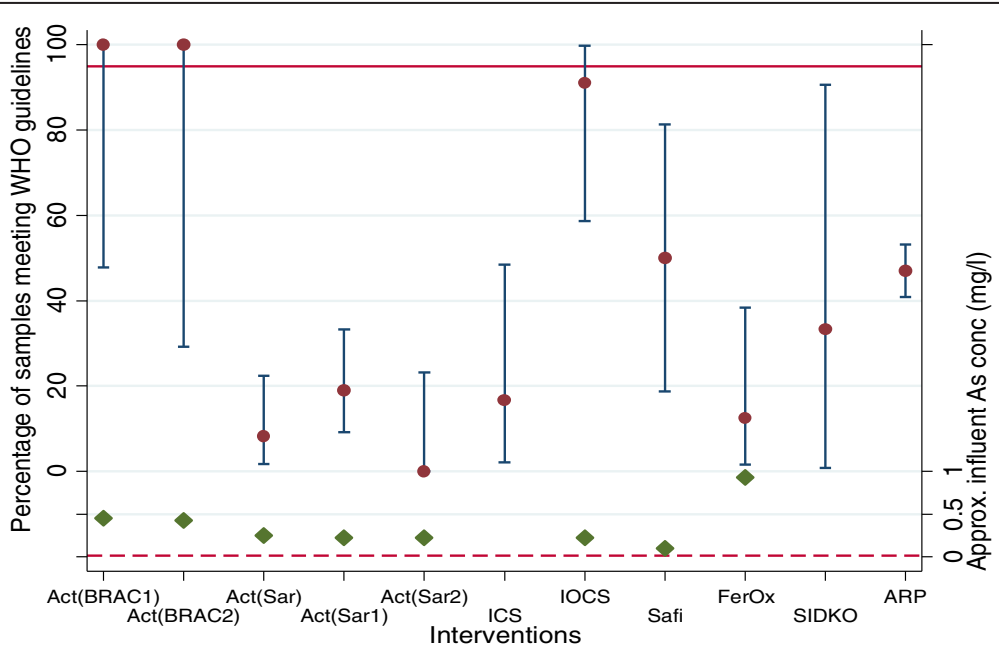

Figure 8 Percentage $(95 \% \mathrm{Cl})$ of samples meeting WHO guidelines for adsorption technologies. Act(BRAC1) and Act(BRAC2), activated alumina for two units [27]; Act(Sar), activated alumina [46]; Act(Sar1) and Act(Sar2), activated alumina for two time-periods [3]; ICS, iron coated sand [21], IOCS, iron oxide coated sand [47]; Safi [38]; FerOx, ferric oxide [24]; SIDKO [27]; ARP, arsenic removal plant [48]. 


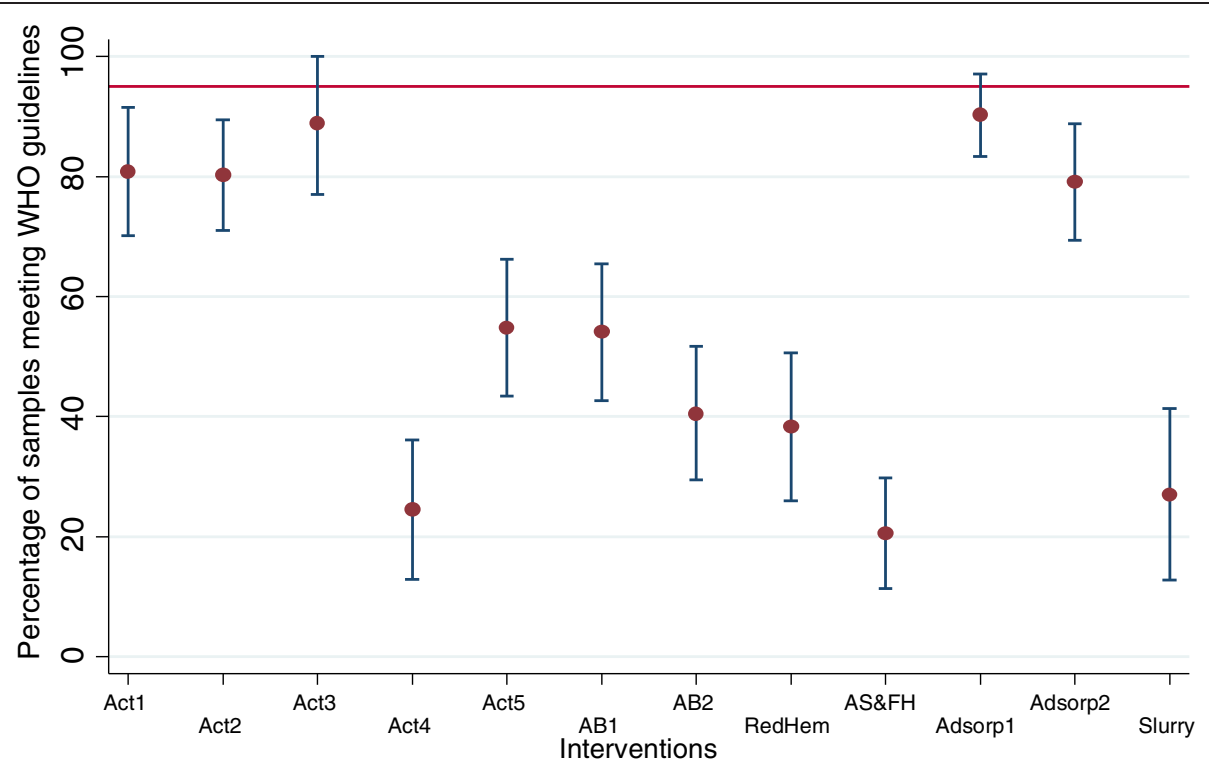

Figure 9 Percentage $(95 \% \mathrm{Cl})$ of samples meeting WHO guidelines for adsorption technologies [45]. Act1-Act5, activated alumina at five sites; AB1 and AB2, Aqua Bind at two sites; RedHem, red haematite; AS\&FH, aluminium silicate and ferric hydroxide; Adsorp1 and Adsorp2, AdsorpAs at two sites; Slurry, slurry/granular ferric hydroxide.

precipitation and filtration technologies. One study provided data separately for six different wells and so the data in Figure 7 correspond to ten individual interventions. Based on data from these ten interventions, the coagulation, co-precipitation and filtration technologies appear to perform better than the oxidation and filtration technologies, with five of the nine technologies having $\geq 50 \%$ of samples meeting WHO guidelines (see Figure 7). The best performing technology, the alum iron coagulation (AIC), is reported by Ashraf Ali et al. (2001) to have $83 \%$ of samples meeting WHO guidelines with a $95 \%$ CI of $52 \%$ to $98 \%$ [21]. The width of the $95 \%$ CIs associated with all of these estimates (except those for BP and ferric alum (BP Fer) and Procter and Gamble Powder (P\&G)) indicates a small number of samples analysed and reported. Note that where data are available, the influent As concentrations are well above the WHO guideline (solid diamonds on Figure 7).

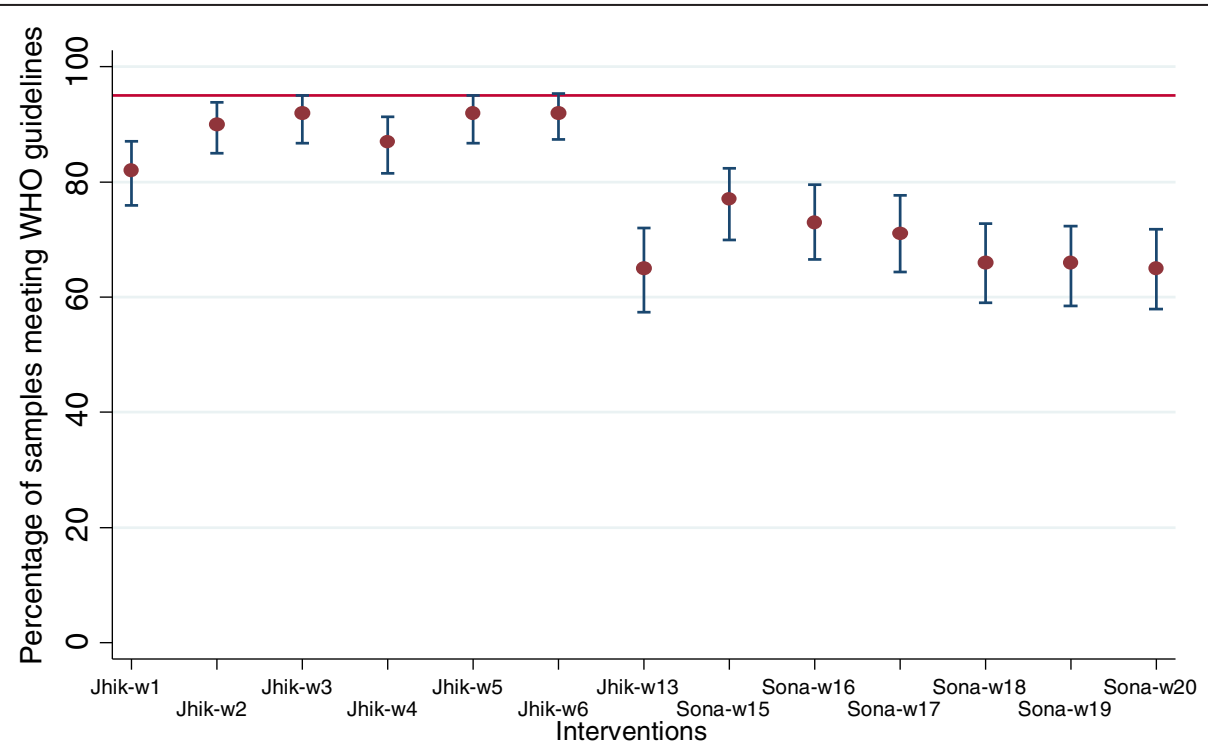

Figure 10 Percentage $(95 \% \mathrm{Cl})$ of samples meeting WHO guidelines for zero valent iron technologies (specifically from BRAC (2001). 


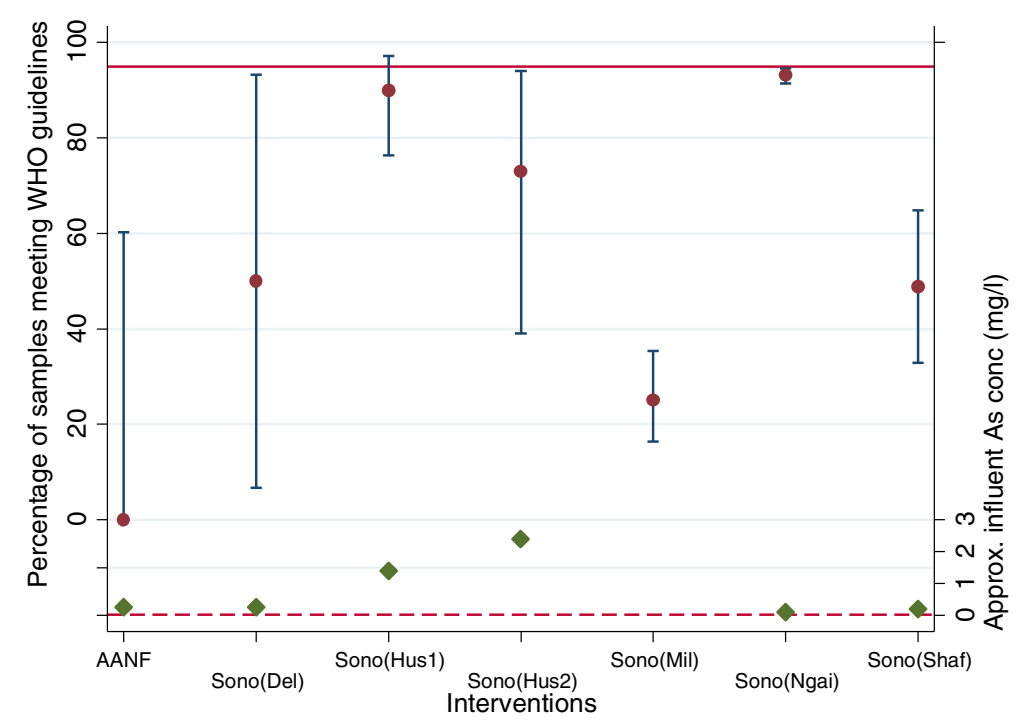

Figure 11 Percentage $(95 \% \mathrm{Cl})$ of samples meeting WHO guidelines for zero valent iron technologies (from sources other than BRAC (2001). AANF, Asia arsenic network filter [42]; Sono(Del), Sono [42]; Sono(Hus1) and sono(Hus2), sono for 2 filters [49]; Sono(Mil), sono [17]; Sono (Ngai), sono[23,30]; Sono(Shaf), Sono [32].

\section{Adsorption technologies}

Out of 13 studies, data are available from ten on the percentage of samples meeting WHO guidelines. For nine of these ten studies results for 11 unique interventions are available as one study reports on an intervention separately for two different time-periods (Sarkar et al., 2008 for the activated alumina) [3] and another reports separately for two different sites (BRAC for the activated alumina) [27]. Thus, 11 estimates of the percentage of samples meeting WHO guidelines from nine of the ten studies are shown in Figure 8.
The study by Hossain et al. (2005) evaluated six distinct interventions over 12 sites (Figure 9): activated alumina interventions placed at separate five sites (Act1Act5), Aquabind (AB1, AB2) placed at two sites, Adsorp As (Adsorp1 and Adsorp2) placed at two sites, red haematite (RedHem) placed at one site, aluminium silicate and ferric hydroxide (AS\&FH) at one site and slurry/granular ferric hydroxide (Slurry) at one site [45]. The results for these 12 interventions are given in Figure 9 and have been separated from the other studies within this group for clarity.

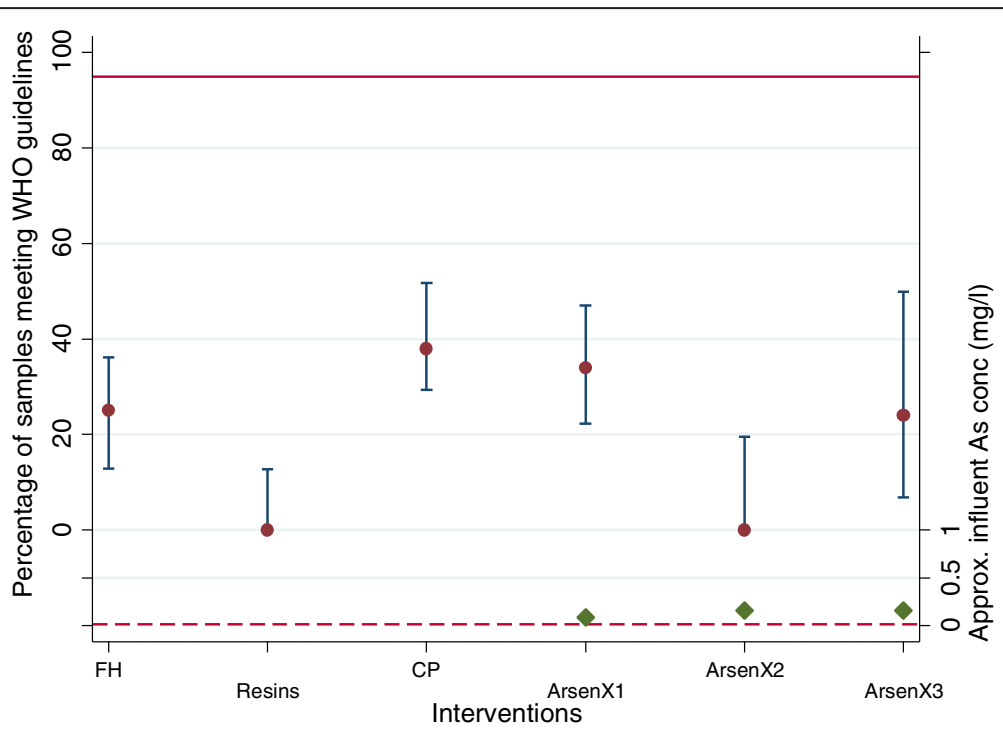

Figure 12 Percentage $(95 \% \mathrm{Cl})$ of samples meeting WHO guidelines for ion exchange technologies. FH, ferric hydroxide[45]; Resins, bucket of resins [45]; CP, catalytic precipitation [45]; ArsenX1 - ArsenX3, ArsenX for single and split columns [50]. 
The results for the total of 23 interventions suggests a great deal of variation in effectiveness, with two technologies having $100 \%$ of samples meeting WHO guidelines (see Figure 8: Act(BRAC1) and Act(BRAC2)), while over half of the technologies have $<50 \%$ of samples meeting WHO guidelines. The iron oxide coated sand technology (IOCS) performs well with $91 \%$ of samples having As concentrations $\leq 0.01 \mathrm{mg} / \mathrm{L}$. However, as with the technologies described above, there is a great deal of uncertainty in the majority of these estimates as the number of samples reported is often low (reflected in the wide 95\% CIs). Note that the approximate influent As water concentrations, where available, are well above the WHO guideline.

\section{Zero-valent technologies}

Six of the 13 effectiveness studies provided data to calculate the percentage of effluent water samples meeting WHO guidelines. Three of these studies reported data separately for more than one individual intervention: Delowar et al. (2006) report on the Asia Arsenic Network Filter (AANF) and sono filter [42]. Hussam and Munir (2007) report on the sono filter at two different locations [49] and the BRAC report presents data for two wells over different time periods [27]. However, BRAC (2001) only reports on the percentage of effluent samples where arsenic concentrations were $0 \mathrm{mg} / \mathrm{L}$. These data are shown in Figure 10.

The results from BRAC (2000) suggest that the sono filter performs reasonably well with $>80 \%$ of samples having $0 \mathrm{mg} / \mathrm{L}$ of arsenic at the Jhikargachha site in the first six weeks of use [27]. For the Sonargaon site, after
15 weeks of use the percentage of samples having $0 \mathrm{mg} / \mathrm{L}$ is $60-80 \%$.

Effectiveness data on zero valent iron interventions from other sources are shown in Figure 11. There is great variation in these estimates, with data on the sono filter implemented by Hussam and Munir (2007) [49] at one particular location (SonoHus1)) and the sono filter implemented by Ngai et al. (2006) (Sono(Ngai)) [23] suggesting good performance.

\section{Ion exchange technologies}

Data from two studies on five different ion exchange interventions, where one intervention is reported separately at two different locations, are available to calculate the percentage of samples meeting WHO guidelines. These data are presented in Figure 12, and suggest that ion exchange technologies are poor at reducing arsenic concentrations to within WHO guidelines, with the best performing intervention, catalytic precipitation as implemented by Hossain et al. (2005), having just 39\% of samples meeting WHO guidelines [45].

\section{Arsenic removal in situ, membrane and electrolytic technologies}

As displayed in Figure 13, evidence from the two studies providing data on subterranean arsenic removal (SAR) ((1)SAR(Gupta)) and (1)SAR(V.Halem)) is inconsistent, with the SAR reported in Gupta having $72 \%$ of samples meeting WHO guidelines, while the percentage of samples meeting WHO guidelines in the Van Halem et al. (2010) study is just 6\% [51].

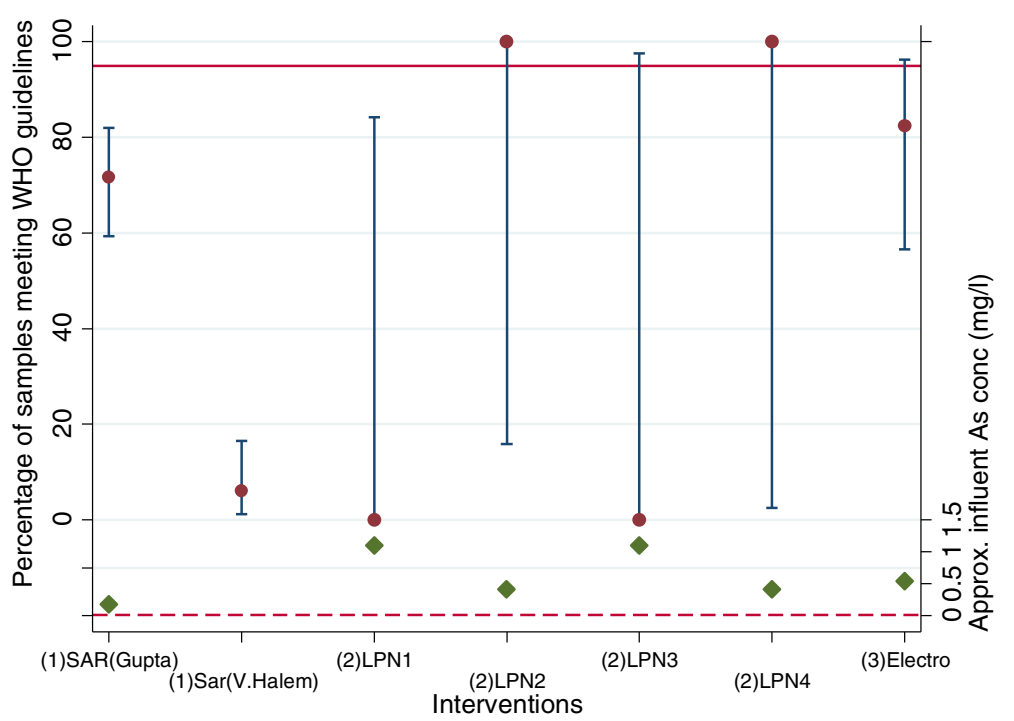

Figure 13 Percentage $(95 \% \mathrm{Cl})$ of samples meeting WHO guidelines for arsenic removal in situ, membrane and electrolytic technologies. (1)SAR(Gupta), subterranean arsenic removal [52]; (1)SAR(V.Halem), subterranean arsenic removal [51]; (2)LPN1 - (2)LPN4, low pressure nanofiltration for four sites [22]; Electro, electrocoagulation [53]. 
Table 10 Summary of effectiveness evidence for oxidation and filtration interventions

\begin{tabular}{|c|c|c|}
\hline Intervention & Study & $\begin{array}{l}\text { Effectiveness } \\
\text { evidence }\end{array}$ \\
\hline \multirow[t]{3}{*}{ AIRP \& AJIRU } & Al-Muyeed & \\
\hline & Hassan 2008 & \\
\hline & Sharma & \\
\hline Modified Garnet & Amin & \\
\hline \multirow[t]{4}{*}{ Garnet } & BAMWSP & \\
\hline & Rahman 2005 & \\
\hline & Sutherland 2001 & \\
\hline & Sutherland 2002 & \\
\hline \multirow[t]{2}{*}{ Ardasha } & BAMWSP & \\
\hline & Sutherland 2001 & \\
\hline \multirow[t]{3}{*}{ Passive sedimentation } & BAMWSP & \\
\hline & Hoque & \\
\hline & Sutherland & \\
\hline Sand filter & Berg 2006 & \\
\hline Domestic clay candle & Bhattacharyya & \\
\hline SPACE ARP & Brennan & \\
\hline NIFSF & Delowar & \\
\hline Iron oxidising baceria & Hassan 2009 & \\
\hline Iron removal ceramic & Shafiquazaman & \\
\hline
\end{tabular}

${ }^{1}$ Depending on location.

Evidence for the effectiveness of nanofiltration is poor, as it is only based on two samples at two sites, hence the great width of the confidence intervals. However, the evidence from the only study evaluating electrocoagulation as a technology suggest this performs reasonably well with $82 \%$ of samples meeting WHO guidelines, but it does not reach our criteria for excellent evidence of effectiveness [53].

\section{Secondary outcome: Percentage of samples meeting national guidelines for As concentrations}

As Figure 5 shows, much more data are available from the included studies to calculate the percentage of samples meeting national guidelines than for WHO guidelines. This is perhaps due to the national guideline being seen as more achievable than the WHO guideline for arsenic concentrations in groundwater, but also field testing kits may have difficulty measuring at the WHO guidelines for arsenic concentrations in groundwater [1]. For all countries in which these studies were conducted (Bangladesh, India, Nepal, Cambodia, Vietnam and China), the national guideline for arsenic concentrations in groundwater is $0.05 \mathrm{mg} / \mathrm{L}$. This therefore helps comparison across studies and interventions for this outcome.
Table 11 Summary of effectiveness evidence for coagulation, co-precipitation and filtration interventions

\begin{tabular}{|c|c|c|}
\hline Intervention & Study & Effectiveness evidence \\
\hline Alum iron coagulation & Ali 2001 & 1 \\
\hline CIWPL & Amiri 2010 & 2 \\
\hline STAR & Amiri 2010 & 3 \\
\hline \multirow[t]{3}{*}{ DPHE } & BAMWSP & \\
\hline & Sutherland 2001 & \\
\hline & Sutherland 2002 & \\
\hline \multirow[t]{5}{*}{ Stevens } & BAMWSP & \\
\hline & Cheng 2004 & \\
\hline & Meng 2001 & \\
\hline & Sutherland 2001 & \\
\hline & Sutherland 2002 & 4 \\
\hline Alum treatment & Hoque 2000 & \\
\hline BP \& ferric alum & Hossain 2005 & \\
\hline P\&G powder & Norton 2009 & \\
\hline
\end{tabular}

${ }^{1}$ Data to inform national guidelines not available.

${ }^{2}$ Mean effluent arsenic concentrations for 6 out of 7 filters was $<0.05 \mathrm{mg} / \mathrm{l}$.

${ }^{3}$ Mean effluent arsenic concentrations for 5 out of 7 filters was $<0.05 \mathrm{mg} / \mathrm{l}$.

${ }^{4}$ For BAMWSP and Cheng good or poor effectiveness depending on location.

It should be noted that although there is evidence that clinical symptoms of arsenicosis may occur at $<0.05 \mathrm{mg} / \mathrm{L}$ [54], it has been argued that attempting to adopt a lower standard in a developing country, when the existing standard has not yet been achieved, may lead to scarce resources being misdirected [1].

\section{Oxidation and filtration}

The evidence on these technologies to reduce or remove arsenic to $\leq 0.5 \mathrm{mg} / \mathrm{L}$ is mixed, with most interventions having $>60 \%$ of samples meeting national guidelines (see Additional file 9, Figures A and B). In particular, three interventions have $100 \%$ of samples meeting national guidelines: the Space ARP evaluated by Brennan (2011) [37], the garnet filter evaluated by Rahman et al. (2005) [38] and the IOB evaluated by Hassan et al. (2008) [40] in location 1. In contrast, the ardasha filter and passive sedimentation technologies have particularly poor performance with $<10 \%$ of samples meeting national guidelines.

\section{Coagulation, co-precipitation and filtration}

Of the three different coagulation, co-precipitation and filtration technologies providing data for this outcome, only the Stevens Institute Technology, as implemented by BAMWSP, Cheng et al. (2004) and Meng et al. (2001), 
Table 12 Summary of effectiveness evidence for adsorption interventions

\begin{tabular}{|c|c|c|}
\hline Intervention & Study & $\begin{array}{l}\text { Effectiveness } \\
\text { evidence }\end{array}$ \\
\hline \multirow[t]{3}{*}{ Iron oxide coated sand } & Ali 2001 & \\
\hline & Petrusevski & \\
\hline & Yuan 2002 & 1 \\
\hline \multirow{4}{*}{$\begin{array}{l}\text { Activated alumina } \\
\text { (not specific) }\end{array}$} & BRAC 2000 & \\
\hline & Hossain $2005 \times 2$ & \\
\hline & Sarkar 2005 & \\
\hline & Sarkar 2008 & \\
\hline \multirow[t]{4}{*}{ Activated alumina (ALCAN) } & Amiri 2010 & \\
\hline & BAMWSO & \\
\hline & Sutherland 2001 & \\
\hline & Sutherland 2002 & 2 \\
\hline \multirow[t]{3}{*}{ Activated alumina (BUET) } & BAMWSP & \\
\hline & Sutherland 2001 & \\
\hline & Sutherland 2002 & \\
\hline Apyron & Amiri 2010 & 3 \\
\hline Nelima & Amiri 2010 & 4 \\
\hline Shapla & Amiri 2010 & 5 \\
\hline Wholly water & Amiri 2010 & 6 \\
\hline Ferric oxide & Anstiss 2001 & \\
\hline SIDKO & BRAC 2000 & 7 \\
\hline \multirow[t]{2}{*}{ Safi } & BRAC 2000 & \\
\hline & Rahman 2005 & \\
\hline Aqua bind & Hossain 2005 & \\
\hline Red hematite & Hossain 2005 & \\
\hline $\begin{array}{l}\text { Aluminium silicate \& } \\
\text { ferric hydroxide }\end{array}$ & Hossain 2005 & \\
\hline Adsorp As & Hossain 2005 & \\
\hline $\begin{array}{l}\text { Slurry/granular ferric } \\
\text { hydroxide }\end{array}$ & Hossain 2005 & \\
\hline ARP & Hossain 2006 & \\
\hline As removal filter & Misra & 8 \\
\hline
\end{tabular}

${ }^{1}$ Data to inform was not available from Ali 2001 or Yuan 2002.

${ }^{2}$ For Amiri 2010, the mean effluent arsenic concentrations for all 7 filters was $<0.05 \mathrm{mg} / \mathrm{l}$.

${ }^{3}$ Mean effluent arsenic concentrations for all 7 filters was $<0.05 \mathrm{mg} / \mathrm{l}$.

4 Mean effluent arsenic concentrations for all 7 filters was $<0.05 \mathrm{mg} / \mathrm{l}$.

${ }^{5}$ Intervention failed.

${ }^{6}$ Intervention failed.

${ }^{7}$ Data to inform was not available.

${ }^{8}$ Mean effluent arsenic concentrations for 7 filters all $<0.01 \mathrm{mg} / \mathrm{l}$.

have any outcomes with $\geq 95 \%$ (see Additional file 9, Figures C and D) $[25,43,44]$. The P\&G powder evaluated by Norton et al. (2009) has $86 \%$ of samples meeting national guidelines [33]. The DPHE/Danida technologies do not perform well across sites and studies, ranging from 3\% to $80 \%$ of samples meeting national guidelines.

\section{Adsorption}

All but one of the adsorption interventions having available data have $>95 \%$ of samples meeting national guidelines, therefore defined in this report as good evidence of effectiveness (see Additional file 9, Figures $E$ and F). The intervention with $<95 \%$ of samples meeting national guidelines is the ARP as investigated by Hossain et al. (2006) [48].

\section{Zero valent}

The zero valent iron technologies are considered to have good evidence of effectiveness with 12 out of the 14 providing available data, having $\geq 95 \%$ of samples meeting national guidelines (see Additional file 9, Figure G). The sono intervention assessed by Milton et al. (2007) [17], the only RCT, has the lowest percentage of all zero valent iron technologies with $65 \%$ of samples meeting national guidelines.

\section{lon exchange}

There is mixed evidence for the effectiveness of ion exchange technologies in terms of the percentage of samples meeting national guidelines for arsenic concentrations in groundwater (see Additional file 9, Figure $\mathrm{H}$ ). The effectiveness of tetrahedron technologies is inconsistent across sites and within studies, ranging from $57 \%$ to $100 \%$ for different sites within the same study [25]. The ArsenX technologies have poor evidence of effectiveness [50].

\section{Arsenic removal in situ, membrane and electrolytic technologies}

Due to the low number of samples assessed in Oh et al. (2000) where membrane technology was evaluated [22], it is difficult to comment on the effectiveness of this technology (see Additional file 9, Figure I). Data on the subterranean arsenic removal in situ interventions is inconsistent ranging from $34 \%$ [51] to $85 \%$ [52]. However, the electrocoagulant technology evaluated by Wan et al. (2011) has $100 \%$ of samples meeting national guidelines (see Additional file 9, Figure I) [53].

\section{Groundwater effectiveness summary}

A summary of the groundwater effectiveness evidence from each study for each intervention evaluated can be found in Tables 10, 11, 12, 13, 14 and 15. They are summarised by their strength of effectiveness evidence as defined in Table 2, p 16. The hollow circles correspond to poor strength of evidence, the crossed-through circles represent good effectiveness evidence with the solid circles representing excellent evidence of effectiveness. For those interventions where the data are inconclusive, no corresponding circle is shown. 
Table 13 Summary of effectiveness evidence for ion exchange interventions

\begin{tabular}{lll}
\hline Intervention & Study & Effectiveness evidence \\
\hline Tetrahedron & BAMWSP & Sutherland 2001 \\
& Sutherland 2002 \\
Ferric hydroxide & Hossain 2005 \\
Bucket of resins & Hossain 2005 \\
Catalytic precipitation & Hossain 2005 \\
ArsenX & Srakar 2007
\end{tabular}

${ }^{1}$ For BAMWSP, good or poor effectiveness depending on location.

In summary, the effectiveness of the oxidation and filtration interventions is poor, while the evidence for coagulation, co-precipitation and filtration, subterranean and membrane and electrolytic methods is mixed with results providing either poor or good evidence for effectiveness. The evidence on adsorption and zero valent iron interventions is more promising with most results suggesting good effectiveness evidence. In particular, the activated alumina and sono three-kolshi/gagri/pitcher filters have $\geq 95 \%$ of samples meeting national guidelines. Disappointingly, only one study reports excellent evidence of effectiveness: BRAC (2000) for activated alumina [27].

\section{Synthesis results - human tissue samples}

Only three of the included studies report on measures of arsenic concentrations in human tissue or body fluids: Milton et al. (2007), Norton et al. (2009) and Hossain et al. (2005) [17,33,45]. Milton et al. (2007) report from their RCT urinary arsenic concentrations from individuals before and after (at one and 12 months post-

\begin{tabular}{|c|c|c|}
\hline Intervention & Study & $\begin{array}{l}\text { Effectiveness } \\
\text { evidence }\end{array}$ \\
\hline \multirow{12}{*}{$\begin{array}{l}\text { Sono 3-kolshi/gagri/ } \\
\text { pitcher }\end{array}$} & BAMWSP & $\boldsymbol{Z}$ \\
\hline & BRAC & $\boldsymbol{\theta}$ \\
\hline & Delowar & $\boldsymbol{Z}$ \\
\hline & Hoque 2004 & \\
\hline & Hussam & $\boldsymbol{Z}$ \\
\hline & Milton & \\
\hline & Neku & \\
\hline & Ngai 2006/7 & 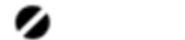 \\
\hline & Shafiquazzaman 2009 & $\boldsymbol{\theta}$ \\
\hline & Sutherland 2001 & $\boldsymbol{Z}$ \\
\hline & Sutherland 2002 & $\boldsymbol{Z}$ \\
\hline & Uy & $\boldsymbol{2}$ \\
\hline AAN filter & Delowar & $\mathrm{C}$ \\
\hline
\end{tabular}

Table 15 Summary of effectiveness of evidence for other interventions

\begin{tabular}{|c|c|c|}
\hline Intervention & Study & Effectiveness evidence \\
\hline \multirow{3}{*}{$\begin{array}{l}\text { Subterranean arsenic } \\
\text { removal in situ }\end{array}$} & Gupta & \\
\hline & Van Halem & \\
\hline & Rott & 1 \\
\hline Membrane technology & $\mathrm{Oh}$ & 2 \\
\hline Electrolytic methods & Wan & $\theta$ \\
\hline
\end{tabular}

${ }^{1}$ Unable to extract data from Rott.

${ }^{2}$ Lack of smaples makes interpretation difficult.

intervention) use of the three-pitcher filter compared to individuals receiving no intervention [17]. They found that for controls, post-intervention urinary arsenic concentrations were statistically significantly greater than the pre-intervention concentrations. Regardless of whether the analysis was restricted to those individuals who selfreported compliance, the post-intervention urinary arsenic concentrations for those receiving the three-pitcher filter were not statistically significantly different to the preintervention concentrations for one and 12 month total urinary inorganic arsenic metabolites, and one month urinary inorganic arsenic. At 12 months, measures of urinary inorganic arsenic were statistically significantly higher than pre-intervention levels for the three-pitcher filter (mean 18.3 vs $24.4 \mu \mathrm{g} / \mathrm{g}$ creatinine). Milton et al. (2007) provide three possible explanations for why postintervention urinary arsenic concentrations were not found to be as low as expected: a) incomplete compliance, b) individuals receiving sources of arsenic through routes other than household consumption, and c) the intervention not being as effective as expected [17].

Hossain et al. (2005) report on the effectiveness of ARPs based on adsorption, ion exchange or oxidation and filtration primary processes [45]. As a secondary analysis to arsenic concentrations in water, they analysed the urine samples of individuals. Hossain et al. (2005) briefly describe their results stating that $82 \%$ of the 150 individuals had urinary arsenic concentrations above the normal limit, two years after the ARPs had first been installed, with a mean of $104 \mu \mathrm{g} / 1.5 \mathrm{~L}$ (SD $116 \mu \mathrm{g} / 1.5 \mathrm{~L}$ ). This was significantly higher than the urinary arsenic concentrations measured in 78 individuals in unaffected areas. Hossain et al. (2005) discuss technical reasons for the lack of effectiveness of the ARPs: maintenance, clogging and lack of user friendliness [45].

Norton et al. (2009) measured total urine arsenic concentration before and after the initiation of the Proctor and Gamble (flocculant-disinfectant) powder in 103 individuals [33]. They report a $42 \%$ reduction over 12 weeks in total urinary arsenic levels from a median of $385 \mu \mathrm{g} / \mathrm{g}$ to $225 \mu \mathrm{g} / \mathrm{g}$. But they note that for 24 of 103 participants, total urinary arsenic levels were actually higher 
Table 16 Maintenance of oxidation and filtration technologies

\begin{tabular}{ll}
\hline Intervention & Comments \\
\hline $\begin{array}{l}\text { Modified Garnet home-made } \\
\text { filter }\end{array}$ & Maintenance - Sand and chips contaminated with As to be washed and disposed of. \\
& Positive - Users appreciated the quality and taste of the water, and its transparency because it was free of iron \\
& (Amin, 2010).
\end{tabular}
(Amin, 2010).

Acceptance satisfactory, particularly with plastic containers as opposed to earthen containers (Hoque et al., 2000).

Negative - Most of the women who operated the filters, faced difficulties reinstalling them. For the washing and drying of the filter materials and moving of the buckets, they needed assistance from other household members. The case studies also revealed that many household heads were not willing to buy the materials (Amin, 2010).

After three months, most of the filters were found to be dirty and without lids and the buckets for storing water were covered by a dirty cloth. Out of eight, five were under operational conditions. Three filters had changed filter bed materials and were treated according to the instructions, whereas two filters, the materials were only washed without changing them. The users of three filters had stopped operation of the filters after two to three months (Amin, 2010).

Two households did not replace the filter bed materials. They reused the materials after washing them, rinsed with $\mathrm{Ca}(\mathrm{ClO})_{2}$ and dried them. For the remaining six households, the disposal of the spent filter materials was carried out in different ways. Two households threw the spent filters materials at the back of their houses on the land. One household used the filter bed materials in construction work and one household replaced the spent materials with new sand and brick chips in the shop for free. The other two households disposed of the spent materials on the cow dung stockpile near their house and covered them with cow dung (Amin, 2010).

Slow flow rates, not enough As free water and heavy to use (Hoque et al., 2004).

Sand filter

Maintenance - Sand is replaced and tanks cleaned with a brush every one to two months

Positive - Users of the community-based option found it technically effective. A keen interest was shown because it was less exposed to outside contaminants compared to the three-pitcher. Also employs indigenous technology (BRAC, 2000).

The visually observable removal of iron from the pumped water makes the effect of sand filters recognisable even to people who are not aware of the arsenic problem. Eighty-two percent of respondents with sand filters would decide again in favour of it. Of households without sand filters, 36\% would decide in favour of it. Forgetting the maintenance does not seem to be a problem since a reduction in water flow and change in colour and taste act as natural reminders (Tobias and Berg, 2011).

Negative - Users have to wait until reservoir is full to use. High initial installation costs. Needs continuous monitoring for clogging and arsenic removal capacity. Chambers need to be covered properly to protect from insects which may put people off (BRAC, 2000).

Problems with space requirement, weight or immobility, and practical problems, such as pumping and filter repair. Other projects like building a new room, buying appliances where given a priority over sand filters. Respondents reported changing the sand in the filters every three to four months. This is near the recommended frequency of changing the sand every three months. However, 52\% changed it less frequently (Tobias and Berg, 2011).

Home based filter (3 pitcher)

Ardasha filter

Passive sedimentation

SPACE AIRPS

AIRPS
Maintenance - Unit to be washed every seven to ten days.

Positive - High acceptance from users (Hoque et al., 2004).

Maintenance - This technology requires cleaning which Brennan and McBean (2011) state users are capable of doing.

Maintenance - Filtration media requires backwashing 2-3 times per week. No current methods of disposal for As contaminated sludge.

Positive - From a survey of 200 users, 100\% were willing to use the system and willing to pay. Only $4 \%$ complained about the maintenance (Abdullah and Rumana, 2006).

Negative - The tubewells and the ARPs belonged to different manufacturers and the matching was often poor, leading to jammed valves, longer collection time, erupting water drenching user (Hossain et al., 2006).

Clogging of ARPS due to sand gushing. Another problem in running ARPs is clogging, which happens due to silvery colloidal sand coming in with water and choking the tubewell and filter media. The ARP manufacturers and the installing authority did not consider this before installation. Each ARP has a fixed media life and after that the media needs to be changed for consistent performance. It was observed that many ARPs required changing their media well before adsorptive capacity due to clogging (Hossain et al., 2006).

Only 30\% of the 432 operational ARPs received regular backwashing, but only 10 out of 131 regularly backwashed ARPs were being backwashed twice a week, which is necessary for efficient performance (Hossain et al., 2006). 


\section{Table 16 Maintenance of oxidation and filtration technologies (Continued)}

\begin{tabular}{|c|c|}
\hline \multirow[t]{3}{*}{ Iron oxidising bacteria } & $\begin{array}{l}\text { Maintenance - May be operated for } 4-7 \text { months without cleaning. If cleaned but not maintained, authors } \\
\text { estimate may operate for five to ten months. }\end{array}$ \\
\hline & $\begin{array}{l}\text { Positive - One person found the operation and maintenance tedious, although this became easier following } \\
\text { gradual modifications resulting in improved effluent flow and reduced cleaning frequency (Hassan et al., 2009). }\end{array}$ \\
\hline & $\begin{array}{l}\text { Negative - Use of calcium hypochlorite on AIRUs with high As influent concentration caused an objectionable } \\
\text { odour (Hassan et al., 2009). }\end{array}$ \\
\hline \multirow[t]{3}{*}{$\mathrm{A} / \mathrm{IRU}$} & $\begin{array}{l}\text { Maintenance - Cleaning was performed by opening the gate valve at the bottom layer of the up flow } \\
\text { roughing filter and flushing out settled sludge through backwashing by hydrostatic pressure. }\end{array}$ \\
\hline & $\begin{array}{l}\text { Positive - From a survey of } 200 \text { users, 100\% were willing to use the system and willing to pay. Only } 4 \% \\
\text { complained about the maintenance (Abdullah and Rumana, 2006). }\end{array}$ \\
\hline & $\begin{array}{l}\text { Negative - The tubewells and the ARPs belonged to different manufacturers and the matching was often poor, } \\
\text { leading to jammed valves, longer collection time, erupting water drenching user (Hossain et al., 2006). }\end{array}$ \\
\hline \multirow[t]{2}{*}{ Iron removal ceramic filter } & Maintenance - Users cleaned filter once a week with hot water and soft cloth or brush. \\
\hline & $\begin{array}{l}\text { Positive - } 80 \% \text { users reported that the filter was easy to maintain and filtered water appeared clear, tasted } \\
\text { better and odourless. Ninety percent used it for one year and were satisfied with it (Shafiquzzaman et al., 2011). }\end{array}$ \\
\hline \multirow{2}{*}{$\begin{array}{l}\text { Asian Arsenic Network (AAN) } \\
\text { Filter }\end{array}$} & Maintenance - Replacement of sand in second pitcher after two months. \\
\hline & $\begin{array}{l}\text { Negative - Removal efficiency of As and flow rate decreased greatly after three month continuous operation } \\
\text { (Delowar et al., 2006). }\end{array}$ \\
\hline \multirow[t]{2}{*}{ NIFSF } & Maintenance - Package and storage (of bleach in particular which has a shelf life of two months). \\
\hline & $\begin{array}{l}\text { Negative - As removal efficiency substantially decreased after two month continuous operation. Issue with } \\
\text { proper packaging and storage particularly of bleaching powder having a very limited shelf life (only two } \\
\text { months) (Delowar et al., 2006). }\end{array}$ \\
\hline
\end{tabular}

after the intervention was initiated than the arsenic levels before.

Norton et al. (2009) provide three possible explanations for what they consider a modest reduction in total urinary arsenic levels: a) the participants consumed water outside of the home where interventions to reduce arsenic were not in place, b) the consumption of food containing high levels of arsenic due, for example, to irrigation, and c) that the body stores arsenic and will release these stores when arsenic consumption decreases [33].

\section{Reasons for variation in effectiveness}

The effectiveness of each technology needs to be understood in context, for example, perception of the arsenic problem by the users, cost, flow rate and maintenance. Therefore, the supporting information from the included studies, has been summarised where available. Please note, it was not within the remit of this review to synthesise or interpret the extracted qualitative data.

\section{Perception of the arsenic problem}

The perception of people using the arsenic mitigation technologies has been shown to be integral to successful implementation of technologies, for example, it took 25 to 30 years to convert up to $97 \%$ of the rural population of Bangladesh to using tubewell water, as opposed to contaminated surface water, and even then it was easier than today's alternative safe water options in terms of acceptance, technical viability, financial and maintenance aspects [55]. Furthermore, there have been instances of confusion due to previous experiences which have delayed uptake of arsenic removal technologies; for example, people using passive sedimentation as originally promoted by some organisations were approached to change their practise again despite having already made an effort to treat arsenic and change their behaviour [56].

General awareness of the arsenic problem is varied. Often, older people did not consider arsenic to be such a problem, particularly if they had been drinking water from the present sources for 25-30 years without noticing any issues. There was a general perception that arsenic was less likely to be considered a problem among illiterate communities [55]. In contrast, Jakariya (2003) also found that in a village with better socioeconomic conditions and higher levels of literacy, people were not willing to accept arsenic may be a problem in the long run [55]. It should be noted they had no individuals displaying the symptoms of arsenicosis. They were aware of the long incubation period of the disease and believed that their better nutritional status helped prevent it; this made the villagers reluctant to use arsenic free water.

Culture can be an issue when attempting to introduce new technologies. There is a 'traditional' practice in some areas that men never collect drinking water. Due to religious perceptions and cultural traditions, rural women avoid any sort of contact, including visual contact, with unknown male persons and non-relatives. This discourages men from fetching water from places where women usually do. If men do collect water they are often taunted for doing women's work [55]. Hence, having to 
Table 17 Maintenance of coagulation, co-precipitation and filtration technologies

\begin{tabular}{ll}
\hline Intervention & Comments \\
\hline DPHE/Danida two bucket & $\begin{array}{l}\text { Negative - For the two kolshi, problems with the distribution of the chemical coagulant packet, as it had to be } \\
\text { shstem }\end{array}$ \\
$\begin{array}{l}\text { shipped from Kathmandu over unreliable road networks. Some users complained about the amount of work } \\
\text { ceramic candle vessels, post coagulation (Ngai et al., 2007). }\end{array}$
\end{tabular}

Alum treatment of

contaminated water

Stevens Institute technology

Household co-precipitation and filtration system

STAR

CIWPL

Procter \& Gamble flocculantdisinfectant powder

Household arsenic removal system

Ferric chloride coagulation
Negative - The water held a residual smell, therefore, people did not accept or use the water (Hoque et al., 2000).

Negative - Main concerns were the technology was difficult to move and produced slow flow rates (Sutherland et al., 2002).

Maintenance - Washing of clogged filter sand.

Maintenance - Disposal of residual flocculant. 10L/sachet. Stir five min and settle five min (Norton et al., 2009).

Negative - Problems with cooking reported on $28 \%$ of visits - primarily associated with preparation of rice and included development of a yellowish discolouration, a bad smell and stickiness. Difficulties with water treatment were reported next most frequently (24\%) and included difficulties with flocculant disinfectant floating on top of the water during treatment rather than settling which made filtration difficult (Norton et al., 2009).

Maintenance - Sand bed resuspended in well water and washed twice a week. Issue with disposal of orange sludge (Meng et al., 2001).

Maintenance - Requires daily addition of chemicals to water and regular supply of chemicals. Washing of straining cloth and sand from twice a week to every two weeks (Ashraf Ali et al., 2001).

Positive - People generally very eager to use units, particularly among those more aware of the adverse effects of arsenic. People were willing to pay for chemical packets. Easy operation and maintenance appears to have made units popular. Impressed with clarity of water - identified by households as primary reason for using the unit (Ashraf Ali et al., 2001).

Negative - Some of the households did not use treated water during the winter because the water was very cold and the tubewell water was much warmer. Also noted that it was difficult for women to stir upper bucket. Observations suggest instructions not strictly followed. Too much work for the mixing and too long for iron flocs to settle (Ashraf Ali et al., 2001).

Chlorinating agent $(\mathrm{BP})+$ Maintenance - Requires periodical sludge removal and/or cleaning (Hossain et al., 2005).

ferric alum

walk further to bring safe water can mean extra work for women. Lack of privacy has also been identified as a barrier to collecting water from the improved water options and some women considered having to go out of their house for water a prestige issue [57].

It would seem that whether a new technology was household- or community-based influenced its success, yet, the issue is complex. Hoque et al. (2004) found that people discontinued the use of all household-based water options after several weeks [57]. One third of these users switched to piped or manual deep tubewell water as it became available. People shared the costs for these options and claimed that walking to a safe, reliable and easily manageable water source once a day was more convenient than operating and maintaining household-based options [57].

An earlier study by Hoque et al., (2000) investigated various methods of implementation for the arsenic removal technologies were employed [56]. Proper education, training and regular sharing of information with the stakeholders were identified as the main driving factors behind the spontaneous participation of villagers. However, lack of information, education and communication materials for the promoting/motivating of stakeholders as well as for people was found to hamper the results.

Overall, understanding how new technologies will be received is highly contextual, not only for the users, but also with regard to the agencies installing them. Hossain et al. (2006) found indiscriminate installation of ARPs without proper preparatory steps, coupled with ill-maintenance, gross mismanagement and a sense of disowning on the parts of the users have resulted in misuse of these costly plants and the treated water [48]. Ngai et al. (2006) also found the Kanchan Arsenic Filter as an open source technology in some cases was not implemented with fidelity and coupled with lack of government approval slowed dissemination and acceptability of the project [23]. This was successfully overcome by training local entrepreneurs to solve problems. Similarly, Jakariya et al. (2007) found 
Table 18 Maintenance of adsorption technologies

\begin{tabular}{l} 
Intervention \\
\hline Activated alumina As-37 \\
Aquabind - activated alumina with metal oxide \\
Red haematite + quartz + sand + activated \\
alumina \\
Activated alumina + AAFS-50, patented \\
aluminium silicate + ferric hydroxide \\
Aluminium silicate + ferric hydroxide \\
Adsorp-As (patented) \\
Slurry/granular ferric hydroxide
\end{tabular}

Samples 305 ARPs - based on typical ARP with granular ferric oxide

BUET activated alumina filter

\section{ALCAN}

Apyron

Wholly Water.

Nelima

Shapla

Tank system with ferric oxide

Safi filter

As removal filter

Well head treatment unit using activated alumina adsorption column

\section{Activated alumina}

Iron oxide coated sand

Iron oxide coated sand

UNESCO-IHE family filter

\section{Comments}

Maintenance - Periodic media replacement at 6-8 months (Hossain et al., 2005).

Maintenance - Requires periodic sludge removal and/or backwash/cleaning (Hossain et al., 2005).

Maintenance - Media recharging at four to six months (Hossain et al., 2005).

Maintenance - Requires periodic backwashing (Hossain et al., 2005).

Maintenance - Requires periodic backwashing two to three times a week (Hossain et al., 2005).

Maintenance - Backwashing twice a week and disposal of backwashed sludge (Hossain et al., 2006).

Maintenance - Media to be replaced after 120,000 L f filtered water. (Sutherland et al., 2002).

Maintenance - Backwashing of media at least once a week for 15 mins to remove silt, sands and iron flocs (Amiri et al., 2010).

Maintenance - Backwashing periodically to remove silt, sands and iron flocs (Amiri et al., 2010).

Maintenance - Regular backwashing of the filter for at least 10 minutes at $\sim 4 \mathrm{~L} / \mathrm{min}$ (Amiri et al., 2010).

Maintenance - Ferric oxyhydroxde replaced $\sim$ after 16 days. The total mass of arsenic produced by the tanks as a max of $\sim 24 \mathrm{~g}$ from $900 \mathrm{~g}$ (dry) ferric oxyhydroxide used per tank per year. A regional centre to deal with the ferric oxyhydroxide renewal/recycling was set up at the University of Rajshahi (Anstiss et al., 2001).

Maintenance - Washing schedule of fifteen days. Candle replacement required after two years (Jakariya, 2003).

Positive - Users preferred it because of formal shape. Allowed continued use of tubewells and was affordable for rural middle-class households (BRAC, 2000).

Negative - Almost half had technical problems: disintegration of candle to broken taps. Clogging of filter, with low flow rates. Capacity of filter to reduce arsenic reduced over time. BRAC Safi was the least favoured technology after 3 pitcher and Alcan (Jakariya, 2003, Jakariya et al., 2005).

Maintenance - The need for waste disposal is mentioned - although the authors indicate the precipitate and sand is converted into concrete blocks. No leaching of arsenic was detected (Misra et al., 2005).

Maintenance - The column is routinely backwashed for 10-15 min every day and the backwash water is passed through a coarse sand filter to retain the HFO particulates (Sarkar et al., 2005).

In situ regeneration - upon adsorption of the column (As conc approaching $50 \mu \mathrm{g} / \mathrm{L}$ ) the unit must be regenerated with $4 \% \mathrm{NaOH}$ followed by $1 \% \mathrm{HCl}$, then water. Takes $\sim 10 \mathrm{hr}$ (Sarkar et al., 2005)

For every regeneration, the mass of sludge (dry weight) added to the top of the coarse filter is less than $400 \mathrm{~g}$. The authors estimate the on- site sand filter many collect and contain spent sludge for over 30 years (Sarkar et al., 2005).

Maintenance - Central facility for regeneration of adsorbent (Sarkar et al., 2005).

Maintenance - Monthly washing of upper sand bed.

Positive - User very happy due to not requiring any chemicals and periodic washing of the sand filter to maintain flow rate (Ashraf Ali et al., 2001).

Maintenance - Regeneration with 8.0L of 0.2N NaOH (Yuan et al., 2002).

Maintenance - Regular cleaning is necessary. The frequency of washing varied from once a week in the first months of operation, to once a day during rest of period (Petrusevski et al., 2008). 


\section{Table 18 Maintenance of adsorption technologies (Continued)}

\begin{tabular}{ll}
\hline SIDKO & Positive - After filtration water was 'crystal-clear and arsenic free'. High-tech appearance \\
means people keen to use it (BRAC, 2000). & Negative - Community SIDKO - people found these options demanded too much \\
& attention, they often did not provide the required maintenance (Hoque et al., 2004). \\
& Very low flow rate ( $1 \mathrm{~L} / \mathrm{min})$ due to clogging in plant. Very expensive. Frequent changing of \\
& media with high arsenic and iron concentration in influent, which is costly. Media and \\
& system not locally available (from Germany), but could produce locally in long-run. Produces \\
& sludge which needs to be removed. Unlikely to be sustainable in long-run: maintenance, \\
& sludge \& lots of users. People may not be prepared to travel to plants: observed initially \\
& plant used by 75 families, as other options became available this reduced to 20 families. \\
People have preference for their own water source (BRAC, 2000).
\end{tabular}

Gravel bed with iron sludge

READ-F

that options still in operation were those having highly motivated caretakers using personal initiatives to run the options [26].

\section{Costs and flow rate}

In developing countries cost will clearly be an issue. Many investigators were mindful of this; ensuring interventions used local materials and resources.

Interestingly, Hossain et al. (2006) found that technologies which were free were not seen as an asset by the community and therefore not maintained [48]. It seemed because the villagers had not invested, they felt no sense of ownership. A similar issue was found by BRAC (2000) [27]. None of the village water committees set up by them were taking responsibility for the free demonstration units provided, which subsequently fell into disrepair. BRAC (2000) considered this was either because of minor faults that cost little money to fix or routine maintenance of the options that would need physical labour to replace or regenerate. BRAC (2000) considered it may be that because the villagers did not have to pay, they lost interest, therefore they intend to ensure some community contribution to future projects to create a sense of ownership.

Other studies contradict the hypothesis of ownership. For example, Hoque et al., (2000) found community-based options were used by many families who initially showed no interest in the options at the planning phase and so did not share the costs [56]. A survey by Jakariya (2003) found 54\% of respondents wanted free options from the government or some kind of government help to alleviate the problem, with $64 \%$ saying that they did not want to pay for any type of alternative safe water options [55].

The ability of the technology to produce sufficient water is also key to the success of a technology and should be balanced against cost. As a guide, approximately $50 \mathrm{~L} /$ day is considered an acceptable volume for a family's needs [58]. The following tables summarise the cost and flow rate of technologies, where that information is given. Costs are given as Australian dollars for 2011. Where possible, flow rates have been converted to $\mathrm{L} / \mathrm{hr}$.

Household oxidation and filtration technologies listed in Table 3 display flow rates from 1-60 L/hr, with the majority of technologies achieving 1-5 L/hr. The sand filter, however, reached $60 \mathrm{~L} / \mathrm{hr}$. Community interventions achieved 140-200 L/hr. The costs within this group, where given, appear relatively low, presumably due to the use of local materials, such as sand.

With regard to the coagulation, co-precipitation and filtration group, flow rate is not necessarily a practical measure since some interventions involve only adding a powder, followed by stirring and settling. However, an estimate can be made of the production rate of arsenic free water (see Table 4) e.g. Star/CIWPL, 16-20 L after mixing and standing from $15 \mathrm{~min}$ to an hour. Otherwise the range for household technologies was 4.3-120 L/hr. The one community option produced $1000 \mathrm{~L} / \mathrm{hr}$.

Comparisons with regard to cost are difficult due to the lack of information, however, there are likely to be on-going costs due to the regular need for chemicals.

The range of flow rates for household adsorption technologies is broad (Table 5), from $<1$ to $120 \mathrm{~L} / \mathrm{hr}$. However, the community options appear capable of producing flow rates of 42 to $1000 \mathrm{~L} / \mathrm{hr}$. Unfortunately, information on operational costs was sparse. Capital costs for communities were generally high, in comparison to other technologies.

The zero valent iron technologies generally employ local materials, such as nails, brick chips and sand, therefore they are a comparatively cheap technology. However, as shown in Table 6 flow rates appear to be low, at around $2 \mathrm{~L} / \mathrm{hr}$ for a household.

Table 7 shows ion exchange technology to be comparatively expensive and generally a community, as opposed to a household, option. Again, there is little information on operational costs, although start-up costs range from Aus $\$ 1300$ to 5672 . 
Table 19 Maintenance for zero valent iron technologies

Intervention

filter-three gagri-three pitcher

\section{Comments}

Maintenance - Three pitcher filters required cleaning after every four months.

Hussam and Munir (2007) state no special maintenance required other than the replacement of the upper sand layers when the flow rate decreases. The presence of soluble iron and formation of HFO precipitate is also a common problem with other filtration technology. Used sand is considered nontoxic with less than 16 ug/l As.

Positive - Inexpensive. Simple to construct. Made from locally available materials. Uses material familiar to rural people. Still using tubewell water. Portable, so can be relocated. BRAC. Forty five percent of the users were satisfied, $21 \%$ were very satisfied and $4.5 \%$ were not satisfied with the quality of the water based on taste (Shafiquzzaman et al., 2009).

Negative - People did not appreciate maintenance needs (Hoque et al., 2000). The stated reasons for not using Sono filters were: i) they had been injured while cleaning the iron pieces in the filter media, and/or ii) they could not replace/maintain the iron media when it clumped and solidified while used. The pitchers broke frequently during maintenance (Hoque et al., 2004).

Difficult to move and slow flow rates (Sutherland et al., 2002). The three kolshi tended to clog (to $<1 \mathrm{~L} / \mathrm{hr}$ ) after a few months of usage (Ngai et al., 2007).

Produces sludge containing arsenic and potential for contamination with micro-organisms in atmosphere as pitchers not covered (BRAC, 2000).

Bad taste and smells, inadequate amount of water produced by the filter unit, unavailability of filter materials, hazardous maintenance, broken pitchers and water that was too cold to drink were some reasons reported by the participants for not using the three-pitcher filter. People seemed reluctant to collect materials from local market on their own (Milton et al., 2007).

Some problems in terms of leaching of arsenic and clogging in iron filings. In some cases the iron filings were clogged by forming a hard structure (hydrous ferric oxide) which could not be removed from the pitcher (Delowar et al., 2006).

Thirty one filters abandoned after one year, seven broken after six months and 18 abandoned within six months of installation. The connection between the two buckets had been broken in most damaged filters (Shafiquzzaman et al., 2009).

Forty-one percent reported that the filters were frequently clogged and that the flow was too slow to get enough water for their daily needs. About 51\% indicated the cleaning technique was burdensome (Shafiquzzaman et al., 2009).

Households were asked about maintenance. A workshop was conducted before providing the filter. Over $80 \%$ of households had the filter manual, containing guidance for cleaning the filter. However, $80 \%$ of the households performed cleaning based only on the workshop training. One of the reasons may be that it was full of textual rather than pictorial instructions. However, most (about 80\%) of the households were knowledgeable about the maintenance of the filter and they maintained it or cleaned it once or twice a week (Shafiquzzaman et al., 2009).

According to the manual, the sludge should be kept in a pot for environmental safety. Most users disposed of the sludge either in drains (58\%) or directly in ponds (35\%) (Shafiquzzaman et al., 2009).

Kanchan filter

Maintenance - Replacement of nails every three years. Filter cleaning every one to three months (Ngai et al., 2007).

Positive - In terms of social acceptability, the Kanchan filter ranked better than the three or two Kolshi, for example, the slow flow of the three kolshi caused some users to skip filtration when they had no time. Ngai (2007) 83\% sustained use after one year. 86\% found it simple to use. Eight-five percent would recommend (Ngai et al., 2007).

Tubewell sand filter

The subterranean method of arsenic removal in Table 8 shows impressive flow rates of 167-1200 L/hr. Electrocoagulation and nanofiltration, which are more likely to be household options display respectable flow rates of $50 \mathrm{~L} / \mathrm{hr}$ and $17 \mathrm{~L} / \mathrm{hr}$, respectively. Again, information on cost is minimal.

\section{Maintenance}

The level of maintenance required appears to be a key factor in the success or failure of arsenic removal technologies in developing countries. In some cases, it was not only the user who was unclear about the need for maintenance, for example, Hossain et al. (2006) found that authorities responsible for installation and upkeep of ARPS had no clear idea regarding frequency of backwashing [48].

It should also be noted, some of the technologies generate waste, which may or may not be contaminated with arsenic. Often, since there were no specific regulations in regard to the disposal of arsenic-laden spent regenerant on the Indian subcontinent, this waste is disposed of in the open field $[46,48]$. 
Table 20 Maintenance for ion exchange technologies

\begin{tabular}{ll}
\hline Intervention & Comments \\
\hline AFDWS-2000 (patent pending) & Maintenance - Requires periodical sludge removal or backwash (Hossain et al., 2005). \\
Ferric hydroxide & - \\
Bucket of resins (patented) & Negative - Sutherland et al. (2002) reported an issue with taste, smell and costs. \\
Tetrahedron/Tetratreat & $\begin{array}{l}\text { Maintenance - Filter needs to be backwashed every morning for 10-15 minutes. Fresh or regenerated media } \\
\text { is required upon exhaustion of adsorption column. Potential issues with sludge disposal (Sarkar et al., 2007). }\end{array}$ \\
\hline
\end{tabular}

The tables below (Tables 16, 17, 18, 19, 20 and 21) indicate details on required maintenance, as reported, accompanied by views of the users, where available.

\section{Review limitations}

This review is limited primarily by the reporting and conduct of research in the included papers. All but one of the studies was assessed as weak due to poor reporting standards. Our primary outcome (percentage of samples meeting WHO guidelines) could not be determined from many of the study reports. It is unclear if this introduces outcome reporting bias into the review. For example, we have been unable to determine whether outcomes were not reported because none of the samples met the WHO guideline, or simply because older testing kits were not capable of measuring at this level.

\section{Reviewers' conclusions}

Establishing the effectiveness of interventions to reduce the impact of arsenic contamination of groundwater on human health in developing countries is complex. Using systematic review methods, we were able to summarise evidence for the effectiveness of interventions, with the caveat that there were significant methodological weaknesses in much of the underlying research:

- Poor evidence of effectiveness:

$\mathrm{O}$ oxidation and filtration

$O$ ion exchange

- Mixed evidence of effectiveness:coagulation, coprecipitation and filtration

O subterranean (As removal in-situ)

O membrane technologies

O electrolytic methods
- Good evidence of effectiveness:

$O$ adsorption (with $\geq 95 \%$ of activated alumina samples meeting national guidelines)

$\bigcirc$ zero valent iron (with $\geq 95 \%$ of sono three-pitcher filters samples meeting national guidelines)

We did not locate any evaluations of the effectiveness of lime softening or phytofiltration technologies.

Through extracting data about the implementation of interventions, we were also able to summarise some of the complexity of the contexts into which these interventions were introduced. These contexts may begin to explain why the effectiveness of interventions to reduce the impact of arsenic contamination of groundwater can vary greatly, although our findings here did not enable us to rank these issues in order of importance. Consideration of the following issues in decision-making about funding of interventions may be pivotal in whether or not they are effective and have the desired positive impact on human health in developing countries:

- Acceptability to users - technologies that are timeconsuming to draw sufficient water from for a family's needs or require frequent maintenance were unlikely to be used, thereby substantially limiting positive human health outcomes no matter how effective the underlying technology.

- Sense of ownership - communities' willingness-to -pay for technologies varied greatly, with no clear pattern to indicate why this might be the case. Participation may be one explanation, as this was found to vary widely with the extent of education, training and regular sharing of information in the implementation of arsenic mitigation programmes.

Table 21 Maintenance for subterranean arsenic removal and electrocoagulation

\begin{tabular}{ll}
\hline Other & Comments \\
\hline Intervention & - \\
Low pressure nanofiltration - membrane filtration & Maintenance - No additives and no sludge handling (Van Halem et al., 2010, Gupta, 2010). \\
Subterranean arsenic removal & Negative - Units not always operated as per instructions - pump not switched on or \\
Electrocoagulation & carrying out electrocoagulation for less than three hours (Wan et al., 2011). \\
\hline
\end{tabular}


- Perception - the perception of the problem is likely to be integral to behaviour change. Proper education, training and regular sharing of information with the stakeholders have been identified as the main driving factors behind the participation of villagers.

- Women's role in society - following the introduction of technologies, changes to the location of (or frequency at which) women collect drinking water may clash with cultural expectations about women's role in a community. The effectiveness of technologies may ultimately be rooted in community development programmes addressing gender inequalities.

We identified significant shortcomings in the rigour of the studies eligible for inclusion in this review. To improve the evidence-base for decision-making about the effectiveness of interventions about arsenic mitigation technologies at household- and community-level will require commissioning of primary research that:

- reports the number of samples meeting WHO guidelines.

- collects and tests an adequate number of water samples, and uses valid and reliable tools for measuring arsenic concentrations in water.

- reports the characteristics and properties of the intervention

- meets reporting guideline standards appropriate to the study design used; this could facilitate both the process of quality appraisal and the establishment of a common metric to enable comparison across studies in subsequent reviews.

- tests the impact of key implementation contextual factors (e.g. maintenance, culture, organisational support) on outcomes.

Research methods in the field of international development are developing in order to address the complexity of the situation and produce a more informative evidence base for decision makers. As highlighted by the challenges in this review, commissioners should pay close attention to these methods in both primary and secondary research.

The importance of understanding 'how, when and why' interventions are effective, as opposed to simply 'are' they effective, has been highlighted with the perspective of international development by Svoronos and Mate (2011) [59]. Context-specific evaluation designs such as randomised controlled trials with greater protocol flexibility, process evaluations, realist evaluation, and multiple case study designs may provide more nuanced understanding of the effectiveness of complex interventions [59]. It follows from this that systematic reviews of research in international development may also need to accommodate similar context-specificity and apply the principles of conventional systematic reviews rather than the methods in their entirety [60]. Context-specific systematic review methods developed in the health and social policy fields of high-income countries, which integrate quantitative and qualitative data [61-63], may prove fruitful methodological avenues to pursue in synthesising complex evidence for international development.

\section{Additional files}

Additional file 1: Further information on searches.

Additional file 2: List of developing countries as defined by AusAID.

Additional file 3: Sample quality appraisal form.

Additional file 4: Sample data extraction form.

Additional file 5: Summary of study characteristics.

Additional file 6: A general key to Additional file 5 .

Additional file 7: Quality appraisal of articles.

Additional file 8: Explanation for incomplete results.

Additional file 9: Samples meeting national guidelines for As concentration in groundwater.

\section{Competing interests}

None identified. This research has been funded by the Australian Agency for International Development (AusAID). The Commonwealth of Australia accepts no responsibility for any loss, damage or injury resulting from reliance on any of the information or views contained in this publication. Funding for development of the review proposal was provided by the National Institute for Health Research (NIHR) Collaboration for Leadership in Applied Health Research \& Care (CLAHRC) for the South West Peninsula. The views expressed in this publication are those of the authors and not necessarily those of the Commonwealth of Australia, the NHS, NIHR or the Department of Health.

\section{Authors' contributions}

TJH led the systematic review, performed data extraction, quality appraisal, wrote the section on contextual issues and drafted the manuscript. JP performed data extraction, quality appraisal, compiled the section on study characteristic, performed the quantitative analysis and provided methodological guidance. RW performed data extraction, quality appraisal and contributed to the writing of the manuscript. CC scoped and designed the search strategy and conducted the database searches. HE and MD provided substantive topic-specific input. MP led on protocol design, supervised the conduct of the review and provided methodological guidance. All authors commented on and approved the final manuscript.

\section{Acknowledgements}

We would like to thank Will Stahl-Timmins for his assistance with the Gofer software (w.stahl-timmins@exeter.ac.uk).

\section{Author details}

${ }^{1}$ Peninsula Technology Assessment Group, University of Exeter Medical School, Veysey Building, Salmon Pool Lane, Exeter EX2 4SG, UK. ${ }^{2}$ School of Geography, Earth and Environmental Sciences (SoGEES), Plymouth University, Drake Circus, Plymouth PL4 8AA, UK. ${ }^{3}$ European Centre for Environment and Human Health, University of Exeter Medical School, St Luke's Campus, Magdelen Road, Exeter EX1 2LU, UK.

Received: 12 April 2013 Accepted: 26 April 2013

Published: 31 May 2013 


\section{References}

1. Ravenscroft P, Brammer H, Richards K: Arsenic. A Global Synthesis. Wiley-Blackwell: Pollution; 2009

2. Rahman MM, Mukherjee D, Sengupta MK, Chowdhury UK, Lodh D, Chanda CR, Roy S, Selim M, Quamruzzaman Q, Milton AH, Shahidullah SM, Rahman MT, Chakraborti D: Effectiveness and reliability of arsenic field testing kits: are the million dollar screening projects effective or not? Environ Sci Technol 2002, 36:5385-5394.

3. Sarkar S, Blaney LM, Gupta A, Ghosh D, Sengupta AK: Arsenic removal from groundwater and its safe containment in a rural environment: validation of a sustainable approach. Environ Sci Technol 2008, 42:4268-4273.

4. WHO: Guidelines for drinking-water quality, Arsenic in drinking-water. Geneva: WHO Press; 2011.

5. Chakraborti D: Encyclopedia of environmental health: arsenic occurrence in groundwater. Elsevier; 2011.

6. Mohan D, Pittman CU Jr: Arsenic removal from water/wastewater using adsorbents - a critical review. Journal of Hazardous Materials 2007, 142:1-53.

7. Kinniburgh DG, Smedley PL (Eds): Arsenic contamination of groundwater in Bangladesh, Volume 2: Final report (British Geological Survey WC/00/19). Keyworth: British Geological Survey; 2001.

8. Tomlinson R, Rizvi A, Salinas R, Garry S, Pehr J, Rodriguez F: The influence of Google on urban policy in developing countries. International Journal of Urban and Regional Research 2010, 34:174-189.

9. Otike J: The acquisition of grey literature in developing countries, Proceedings of the first international conference on grey literature held at the RAI congress centre. GreyNet, Amsterdam; 1994.

10. NICE: Methods for the development of NICE public health guidance. London: NICE; 2009.

11. Bland M: An Introduction to Medical Statistics. Oxford: Oxford University Press; 2000.

12. Shemilt ITJ, Morciano M: A web-based tool for adjusting costs to a specific target currency and price year. Evidence and Policy 2010, 6:51-59.

13. Higgins JPT, Green S (Eds): Cochrane handbook for systematic reviews of interventions. Version 5.1.0. Oslo: The Cochrane Collaboration; 2011.

14. NHS Centre for Reviews and Dissemination: CRD's Guidance for undertaking reviews in health care. 2 nd edition. York: NHS Centre for Reviews and Dissemination; 2009.

15. Stanley TD, Jarrell SB: Campbell Collaboration statistical analysis policy brief. Oslo: Campbell Collaboration; 2004.

16. Pettiti D: Meta-analysis, decision analysis and cost-effectiveness analysis, Methods for quantitative synthesis in medicine. USA: Oxford University Press; 2000.

17. Milton AH, Smith W, Dear K, Ng J, Sim M, Ranmuthugala G, Lokuge K, Caldwell B, Rahman A, Rahman H, Shraim A, Huang D, Shahidullah SM: A randomised intervention trial to assess two arsenic mitigation options in Bangladesh. Journal of Environmental Science and Health Part A, Toxicl Hazardous Substances \& Environmental Engineering 2007, 42:1897-1908.

18. Akmam W, Higano $Y$ : Arsenic contamination in groundwater in Bangladesh: Supplying safe water with special reference to three villages in Meherpur District. Journal of Bangladesh Studies 2002, 4:25-36.

19. Ahmad J, Goldar B, Misra S: Value of arsenic-free drinking water to rural households in Bangladesh. J Environ Manage 2005, 74:173-185.

20. Ahmad J, Goldar B, Misra S: Rural communities' preferences for arsenic mitigation options in Bangladesh. Journal of Water Health 2006, 4:463-477.

21. Ashraf Ali M, Badruzzaman A, Jalil M, Hossain M, Hussainuzzaman M, Badruzzaman M, Mohammad O, Akter N: Development of low-cost technologies for removal of arsenic from groundwater, Presented at the BUET-UN International Workshop on Technologies for Arsenic Removal From Drinking Water. Dhaka; 2001:99-120. 99-120.

22. Oh Jl, Yamamoto K, Kitawaki H, Nakao S, Sugawara T, Rahman MM, Rahman $\mathrm{MH}$ : Application of low-pressure nanofiltration coupled with a bicycle pump for the treatment of arsenic-contaminated groundwater. Desalination 2000, 132:307-314.

23. Ngai TKK, Murcott S, Shrestha RR, Dangol B, Maharjan M: Development and dissemination of Kanchan Arsenic Filter in rural Nepal. Wat Sci Tech: Water Supply 2006, 6:137-146.

24. Anstiss R, Ahmed M, Islam S, Khan AW, Arewgoda M: A sustainable community-based arsenic mitigation pilot project in Bangladesh. Int J Environ Health Res 2001, 11:267-274.

25. BAMWSP, DFID, WaterAid: Rapid assessment of household level arsenic removal technologies. UK, Surrey: WS Atkins International; 2001.
26. Jakariya M, Bromssen M, Jacks G, Chowdhury AMR, Ahmed KM, Bhattacharya P: Searching for a sustainable arsenic mitigation strategy in Bangladesh: experience from two upazilas. International Journal of Environment and Pollution 2007, 31:415-430.

27. BRAC: Combating a deadly menace. Dhaka: Bangladesh Rural Advancement Committee; 2000.

28. Amiri A, Morsheda E, Kazi Al, Siraj S, Ahmed S, Akbor MA: Results from the first-round of Bangladesh environmental technology verification support to arsenic mitigation (BETV-SAM) field test. Bangladesh Journal of Scientific and Industrial Research 2010, 45:289-302. 302.

29. BCSIR: Performance evaluation and verification of five arsenic removal technologies, ETV-AM field testing and technology verification program. Dhaka: Bangladesh Council of Scientific and Industrial Research; 2003.

30. Ngai TKK, Shrestha RR, Bipin D, Makhan M, Murcott SE: Design for sustainable development - household drinking water filter for arsenic and pathogen treatment in Nepal. Journal of Environmental Science and Health Part A, Toxic/Hazardous Substances \& Environmental Engineering 2007, 42:1879-1888.

31. Uy D, Ngai T, Mahin T, Samnang C, Saray M, Adam M, Baker D: Kanchan arsenic filter: evaluation and applicability to Cambodia. In Water, sanitation and hygiene: sustainable development and multisectoral approaches Proceedings of the 34th WEDC International Conference, United Nations Conference Centre, Addis Ababa, Ethiopia, 18-22 May 2009. Edited by Shaw R. Loughborough; UK: Water, Engineering and Development Centre (WEDC) Loughborough University of Technology; 2009:734-739. 734-739.

32. Shafiquzzaman M, Azam MS, Mishima I, Nakajima J: Technical and social evaluation of arsenic mitigation in rural Bangladesh. Journal of Health, Population and Nutrition 2009, 27:674-683.

33. Norton DM, Rahman M, Shane AL, Hossain Z, Kulick RM, Bhuiyan MI, Wahed MA, Yunus M, Islam MS, Breiman RF, Henderson A, Keswick BH, Luby SP: Flocculant-disinfectant point-of-use water treatment for reducing arsenic exposure in rural Bangladesh. International Journal of Environmental Health Research 2009, 19:17-29.

34. Amin N: Developing an environmentally appropriate, socially acceptable and gender-sensitive technology for safe-water supply to households in arsenic affected areas in rural Bangladesh, MSc Thesis. The Netherlands; 2010.

35. Berg M, Luzi S, Pham Thi Kim T, Pham Hung V, Giger W, StA $\neg$ ben D: Arsenic removal from groundwater by household sand filters: comparative field study, model calculations, and health benefits. Environ Sci Technol 2006, 40:5567-5573.

36. Abdullah A-M, Rumana A: Investigation of the efficiency of existing iron and arsenic removal plants in Bangladesh. Journal of Water Supply: Research and Technology - Aqua 2006, 55:293-299.

37. Brennan $R$, McBean E: A performance assessment of arsenic-iron removal plants in the Manikganj District of Bangladesh. J Water Health 2011, 9:317-329.

38. Rahman IMM, Hossain MM, Uddin MH, Nazimuddin M, Majid MA: Appraisal of two indigenous household groundwater arsenic removal technologies for Bangladesh under field conditions. Journal of Agriculture and Social Sciences 2005, 1:361-365.

39. Debkumar B, Mukherjee PK, Ray AK, Sengupta S: Arsenic-polluted groundwater in West Bengal: a cost-effective remedy. Current Science 2004, 86:1206-1209.

40. Hassan KM, Ahmed F, Hai Fl, Magram SF: Approaches to development of a user-friendly community based arsenic/iron removal unit in Bangladesh. Research Journal of Environmental Sciences 2008, 2:243-251.

41. Sharma AK, Tjell JC, Mosbaek H: Optimisation of iron removal units to include arsenic removal. Part of: Natural arsenic in groundwater. Occurrence, remediation and management. The Netherlands: Balkema Publishers, A.A./Taylor Francis; 2007.

42. Delowar HKM, Uddin I, bou El Hassan WH, Perveen F, Irshad M, Saiful Islam AFM, Yoshida I: A comparative study of household groundwater arsenic removal technologies and their water quality parameters. Journal of Applied Sciences 2006, 6:2193-2200.

43. Cheng Z, Van Geen A, Jing C, Meng X, Seddique A, Ahmed KM: Performance of a household-level arsenic removal system during 4-month deployments in Bangladesh. Environ Sci Technol 2004, 38:3442-3448.

44. Meng ZG, Korfiatis GP, Christodoulatos C, Bang S: Treatment of arsenic in Bangladesh well water using a household co-precipitation and filtration system. Wat Res 2001, 35:2805-2810. 
45. Hossain MA, Sengupta MK, Ahamed S, Rahman MM, Mondal D, Lodh D, Das B, Nayak B, Roy BK, Mukherjee A, Chakraborti D: Ineffectiveness and poor reliability of arsenic removal plants in West Bengal, India. Environ SCi Technol 2005, 39:4300-4306.

46. Sarkar S, Gupta A, Biswas RK, Deb AK, Greenleaf JE, SenGupta AK: Well-head arsenic removal units in remote villages of Indian subcontinent: field results and performance evaluation. Wat Res 2005, 39:2196-2206.

47. Petrusevski B, Sharma S, Kruis F, Khan M, Barua M, Schippers JC: Four years of development and field-testing of IHE arsenic removal family filter in rural Bangladesh. Wat Sci Tech 2008, 58:53. 53.

48. Hossain MA, Amitava M, Sengupta MK, Sad A, Bhaskar D, Bishwajit N, Arup P, Rahman MM, Dipankar C: Million dollar arsenic removal plants in West Bengal, India: useful or not? Water Quality Research Journal of Canada 2006, 41:216-225.

49. Hussam A, Munir AKM: A simple and effective arsenic filter based on composite iron matrix: development and deployment studies for groundwater of Bangladesh. J Environ Sci Health A Tox Hazard Subst Environ Eng 2007, 42:1869-1878.

50. Sarkar S, Blaney LM, Gupta A, Ghosh D, SenGupta AK: Use of ArsenX(np), a hybrid anion exchanger, for arsenic removal in remote villages in the Indian subcontinent. Reactive and Functional Polymers 2007, 67:1599-1611.

51. Van Halem D, Heijman SG, Johnston R, Huq IM, Ghosh SK, Verberk JQ, Amy GL, Van Dijk JC: Subsurface iron and arsenic removal: low-cost technology for community-based water supply in Bangladesh. Wat Sci Tech 2010, 62:2702-2709.

52. Gupta BS: Water treatment goes underground. Chemical Engineer 2010, $1: 35-37$.

53. Wan W, Pepping TJ, Tuhin B, Sanjeev C, Giammar DE: Effects of water chemistry on arsenic removal from drinking water by electrocoagulation. Water Research (Oxford) 2011, 45:384-392.

54. Ahsan $\mathrm{H}$, Chen $\mathrm{Y}$, Parvez F: Arsenic exposure from drinking water and risk of premalignant skin lesions in Bangladesh: baseline results from the Health Effects of Arsenic Longitudinal Study. American Journal of Epidemiology 2006, 163:1138-1148.

55. Jakariya M: The use of alternative safe water options to mitigate the arsenic problem in Bangladesh: community perspective. BRAC 2003, Research Monograph Series no. 24:61.

56. Hoque BA, Mahmood AA, Quadiruzzaman M, Khan F, Ahmed SA, Shafique SA, Rahman M, Morshed G, Chowdhury T, Rahman MM, Khan FH, Shahjahan M, Begum M, Hoque MM: Recommendations for water supply in arsenic mitigation: a case study from Bangladesh. Public Health 2000, 114:488-494.

57. Hoque BA, Hoque MM, Ahmed T, Islam S, Azad AK, Ali N, Hossain M: Hossain: Demand-based water options for arsenic mitigation: an experience from rural Bangladesh. Public Health 2004, 118:70. 70.

58. Gleick P: Basic water requirements for human activities: meeting basic needs. Water International 1996, 21:83-92.

59. Svoronos T, Mate KS: Evaluating large-scale health programmes at a district level in resource-limited countries. Bulletin of the World Health Organization 2011, 89:831-837.

60. Hagen-Zanker J, Duvendack M, Mallett R, Slater R, Carpenter S, Tromme M: Making systematic reviews work for international development. Secure Livelihoods Research Consortium Briefing Paper 1. London: Overseas Development Institute; 2012

61. Dixon-Woods M, Cavers D, Agarwal S, Annandale E, Arthur A, Harvey J, Hsu R, Katbamna S, Olsen R, Smith L, Smith L, Riley R, Sutton A: Conducting a critical interpretive synthesis of the literature on access to healthcare by vulnerable groups. BMC Medical Research Methodology 2006, 6:35.

62. Popay J, Roberts H, Sowden A, Petticrew M, Arai L, Rodgers M, Britten N: Guidance on the Conduct of Narrative Synthesis in. A Product from the ESRC Methods Programme: Systematic Reviews; 2006.

63. Pawson R: Evidence-based policy: a realist perspective. London: Sage Publications; 2006.

doi:10.1186/2047-2382-2-11

Cite this article as: Jones-Hughes et al:: Are interventions to reduce the impact of arsenic contamination of groundwater on human health in developing countries effective? A systematic review. Environmental Evidence 2013 2:11.

\section{Submit your next manuscript to BioMed Central and take full advantage of:}

- Convenient online submission

- Thorough peer review

- No space constraints or color figure charges

- Immediate publication on acceptance

- Inclusion in PubMed, CAS, Scopus and Google Scholar

- Research which is freely available for redistribution

Submit your manuscript at www.biomedcentral.com/submit
C Biomed Central 